Review Article

\title{
Targeting Endothelial Function to Treat Heart Failure with Preserved Ejection Fraction: The Promise of Exercise Training
}

\author{
Andreas B. Gevaert, ${ }^{1,2}$ Katrien Lemmens, ${ }^{1}$ Christiaan J. Vrints, ${ }^{1,2}$ and \\ Emeline M. Van Craenenbroeck ${ }^{1,2}$ \\ ${ }^{1}$ Department of Translational Pathophysiological Research and Research Group Cardiovascular Diseases, \\ University of Antwerp, Antwerp, Belgium \\ ${ }^{2}$ Laboratory of Cellular and Molecular Cardiology and Department of Cardiology, Antwerp University Hospital (UZA), \\ Edegem, Belgium
}

Correspondence should be addressed to Andreas B. Gevaert; andreas.gevaert@uantwerpen.be

Received 10 February 2017; Revised 20 April 2017; Accepted 24 April 2017; Published 19 June 2017

Academic Editor: Patricia C. Brum

Copyright (c) 2017 Andreas B. Gevaert et al. This is an open access article distributed under the Creative Commons Attribution License, which permits unrestricted use, distribution, and reproduction in any medium, provided the original work is properly cited.

\begin{abstract}
Although the burden of heart failure with preserved ejection fraction (HFpEF) is increasing, there is no therapy available that improves prognosis. Clinical trials using beta blockers and angiotensin converting enzyme inhibitors, cardiac-targeting drugs that reduce mortality in heart failure with reduced ejection fraction (HFrEF), have had disappointing results in HFpEF patients. A new "whole-systems" approach has been proposed for designing future HFpEF therapies, moving focus from the cardiomyocyte to the endothelium. Indeed, dysfunction of endothelial cells throughout the entire cardiovascular system is suggested as a central mechanism in HFpEF pathophysiology. The objective of this review is to provide an overview of current knowledge regarding endothelial dysfunction in HFpEF. We discuss the molecular and cellular mechanisms leading to endothelial dysfunction and the extent, presence, and prognostic importance of clinical endothelial dysfunction in different vascular beds. We also consider implications towards exercise training, a promising therapy targeting system-wide endothelial dysfunction in HFpEF.
\end{abstract}

\section{Introduction}

Heart failure (HF) is the most frequent cause of hospitalization in people over 65 years, and incidence is still increasing. Despite improved medical management, prognosis is grim, especially for heart failure with preserved ejection fraction (HFpEF) which has a $65 \%$ mortality rate at 5 years [1]. In contrast to heart failure with reduced ejection fraction (HFrEF), timely diagnosis of HFpEF remains a challenge and current standard therapy fails to improve prognosis [2]. Beta blockers and renin-angiotensin-aldosterone axis antagonists, drugs that mainly target the heart and have reduced mortality in $\mathrm{HFrEF}$, had disappointing results in HFpEF trials [3-5]. As such, a "whole-systems" approach has been proposed, moving therapeutic focus in HFpEF away from the cardiomyocyte $[6,7]$.
Although HFpEF emerged as a distinct HF phenotype about three decades ago and about half of patients fall into this category, its pathogenesis remains incompletely understood. Beside advanced age, female sex, and sedentary lifestyle, HFpEF is associated with comorbidities such as arterial hypertension, diabetes, obesity, chronic obstructive pulmonary disease, and renal dysfunction [8]. Cardiac and extracardiac adjustments to these comorbidities can become maladaptive and lead to the HFpEF syndrome, with exercise intolerance as its main symptom. This maladaptation is characterized by structural changes such as myocardial hypertrophy and fibrosis, driven by a neurohormonal imbalance and systemic cytokine overexpression [9]. As a third mechanism, dysfunction of endothelial cells throughout the entire cardiovascular (CV) system has been put forward as the link between comorbidities and the pathophysiology of HFpEF. 


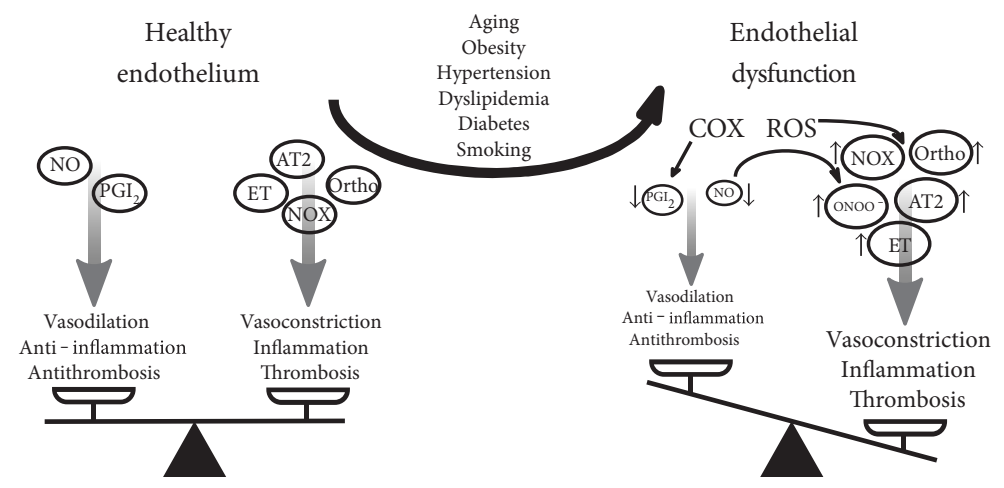

Figure 1: Pathophysiology of endothelial dysfunction. Healthy endothelium maintains a balance between vasodilating, anti-inflammatory, and anti-thrombotic factors on one side and vasoconstricting, inflammatory, and thrombotic factors on the other. In endothelial dysfunction, increased oxidative stress caused by comorbidities tips the balance over to a vasoconstricting, inflammatory, and thrombotic profile. $\mathrm{AT} 2=$ angiotensin 2, $\mathrm{COX}=$ cyclooxygenase, $\mathrm{ET}=$ endothelin, $\mathrm{NO}=$ nitric oxide, $\mathrm{NOX}=$ nicotinamide adenine dinucleotide phosphate oxidase, $\mathrm{ONOO}^{-}=$peroxynitrite, $\mathrm{Ortho}=$ orthosympathetic nerve activity, $\mathrm{PGI}_{2}=$ prostacyclin, $\mathrm{ROS}=$ reactive oxygen species.

This builds on experimental evidence by Brutsaert et al. in the 1980s that the interaction between endothelial cells and cardiomyocytes directly influences diastolic function $[10,11]$.

Clinical endothelial dysfunction (ED) is recognized as a precursor to many CV diseases including HF [12]. Moreover, its prognostic value is proven in cohorts ranging from an unselected general population over patients at risk for $\mathrm{CV}$ disease (hypertension, chronic kidney disease) to patients with established CV disease [13]. Endothelial function is an independent predictor of survival in HF patients [14]. Exercise intolerance, the cardinal symptom in HFpEF, is objectively measured by peak pulmonary oxygen uptake $\left(\mathrm{VO}_{2}\right.$ peak) which is determined by the product of cardiac output and arteriovenous oxygen $\left(\mathrm{O}_{2}\right)$ difference. Hence, both $\mathrm{O}_{2}$ delivery mechanisms (cardiac output, peripheral vascular function) as well as $\mathrm{O}_{2}$ utilizing factors (skeletal muscle) contribute to exercise intolerance [15]. Reduced endothelial-dependent vasodilation on exertion limits systemic $\mathrm{O}_{2}$ delivery, precipitating the switch to an anaerobic metabolism and thereby exacerbating fatigue and dyspnea [16]. ED also forms an attractive therapeutic target due to its reversibility at early stages [17]. This has shifted the search for an effective HFpEF therapy towards interventions correcting ED.

Exercise training is one of the most successful approaches to improve and even correct ED [18, 19]. Exercise-based cardiac rehabilitation programs have already earned their merit by improving symptoms and reducing mortality in various CV diseases, including HFrEF $[20,21]$. The additional beneficial effects on other comorbidities and risk factors make exercise training conceptually a promising therapy for HFpEF [22].

In this review, we will focus on different aspects of ED in HFpEF. First, we briefly review the underlying molecular mechanisms leading to ED. We list the existing evidence on the presence of ED in distinct vascular beds and the clinical importance relative to HFpEF. Finally, the effects of exercise training on endothelial function are discussed, portending important implications for HFpEF treatment.

\section{The Endothelium Is More than a Barrier}

The endothelium was long considered a mere protective layer between the blood and different extravascular tissues. We now know that endothelial cells are dynamic, highly interacting cells regulating blood vessel function and homeostasis. The healthy endothelium prevents platelet and leukocyte adhesion and aggregation, inhibits smooth muscle proliferation, and regulates vascular tone through release of vasoactive substances, all of which are essential in organ perfusion [23]. Nitric oxide (NO) is the major effector molecule, formed from its precursor L-arginine by endothelial NO synthase (eNOS) in response to stimuli such as shear stress, cytokines, and platelet-derived factors. In endothelial cells, NO inhibits expression of leukocyte adhesion molecules, reducing vascular inflammation and atherosclerosis. By diffusing into platelets and vascular smooth muscle cells, NO stimulates the soluble guanylate cyclase-cyclic guanosine monophosphate-protein kinase G (sGC-cGMP-PKG) pathway, hereby inhibiting platelet aggregation and inducing vasorelaxation [23]. NO also diffuses to cardiomyocytes adjacent to coronary microvascular and endocardial endothelial cells, modulating cardiac function [24]. Finally, NO mobilizes stem cells and progenitor cells important for vascular homeostasis and repair [25].

In the setting of $\mathrm{CV}$ disease risk factors (smoking, aging, hypercholesterolemia, hypertension, hyperglycemia, and obesity), the endothelium loses these regulatory functions $[26,27]$. Reactive oxygen species play an important role, reacting with $\mathrm{NO}$ to form toxic peroxynitrite, thereby reducing NO bioavailability. This disturbance of endothelial homeostasis can lead to a vasoconstrictory, proinflammatory, and prothrombotic phenotype at risk for CV disease [12]. The term "endothelial dysfunction" refers to these phenotypic alterations. Figure 1 summarizes the most important molecular influences on healthy and dysfunctional endothelium.

Repair of diseased endothelium does not solely depend on proliferation of existing endothelial cells. Bone marrowderived endothelial progenitor cells can be mobilized to sites 
of endothelial injury or ischemia. They are able to proliferate, exert beneficial paracrine effects through secreting vascular growth factors, and finally integrate into the endothelial layer by differentiating into endothelial cells $[28,29]$.

\section{Evaluation of Endothelial Function}

ED is recognized as the first-but still reversible-step to overt atherosclerosis. As such, several diagnostic evaluation methods have been developed, with the goal to identify high-risk populations and start preventive therapy early. At the other end of the spectrum, presence and severity of ED is related to a negative outcome in established coronary ischemic heart disease and HFrEF [30].

Usually, endothelial function is measured as vasodilation in response to an endothelium-specific stimulus. This includes drugs, such as acetylcholine, but a short period of local ischemia also elicits endothelium-specific hyperemia. The amount of vasodilation can be assessed invasively (e.g., coronary angiography, intravascular flow wires), although noninvasive methods are more widely used nowadays. The percentage dilation of the brachial artery in response to forearm ischemia, measured by ultrasound, is called flowmediated dilation (FMD) [31]. The more recent EndoPAT ${ }^{\mathrm{TM}}$ device (Itamar Medical, Israel) uses a fingertip probe to measure arterial tone. The response to ischemia is calculated automatically and is called reactive hyperemia index (RHI) [32]. Details and advantages of these and other techniques to measure endothelial function have been reviewed previously $[26,33]$. Generally, FMD is considered a measure of the response to shear stress in conduit vessels (macrovascular), which is largely NO dependent, while RHI measures microvascular dilatation to shear stress, which involves other vascular mediators in addition to NO [34].

\section{Endothelial Dysfunction in HFPEF: Cause or Consequence?}

Impaired coronary endothelial-dependent vasodilation was found in nonischemic dilated cardiomyopathy, highlighting the implication of the endothelium in HFrEF regardless of the presence of atherosclerosis [35]. Moreover, ED is not only limited to the coronary arteries, but is equally present in other vascular beds, indicating the systemic nature of ED in HFrEF.

In 2013, Paulus and Tschöpe hypothesized that ED plays a causal role in the development of HFpEF [10]. They postulate that the comorbid illnesses seen in HFpEF are the primary impellent of a systemic inflammatory state, leading to coronary microvascular ED. Indeed, elevated levels of inflammatory cytokines are seen in HFpEF patients [36]. In asymptomatic patients, biomarkers of inflammation predict the onset of HFpEF but not HFrEF [37]. Circulating inflammatory cytokines activate and inflame the endothelium throughout the vascular system, including the coronary microvasculature. This coronary microvascular endothelial inflammation is seen in animal models of HFpEF and in human cardiac biopsies [38, 39].
Reduced endothelium-dependent vasodilation is seen in animal models as well [40].

Reduced NO signaling from dysfunctional endothelium then influences adjacent cardiomyocytes and cardiac fibroblasts through the sGC-cGMP-PKG pathway [24]. Lower myocardial PKG content eventually leads to functional and structural cardiac changes associated with HFpEF [41]. These include delayed myocardial relaxation, increased cardiomyocyte stiffness, cardiac hypertrophy, and interstitial fibrosis [10]. Cardiac-endothelial interaction is reviewed in more detail in 6.2 .

However, a two-way interaction between $\mathrm{HFpEF}$ and ED exists. Once HF develops, the syndrome maintains a vicious circle, further impairing endothelial function. HFpEF itself causes a systemic inflammatory state with high levels of circulating proinflammatory cytokines, increasing production of reactive oxygen species and exerting direct deleterious effects on eNOS expression [42, 43]. Neurohormonal activation in HFpEF increases oxidative stress and activates collagen synthesis [44]. Thus, HFpEF worsens system-wide ED, causing a downward spiral eventually leading to progressive HF.

\section{Clinical Importance: Endothelial Dysfunction as Prognostic Marker in HFPEF}

As there is no universally accepted cutoff for defining ED, the actual prevalence of ED in HFpEF is unknown. In community studies, endothelial function declines with age and presence of CV risk factors [45, 46]. Understandably, FMD and RHI values are lower in populations with established CV disease, including HF patients $[14,47]$. In one of the first studies proving reduced RHI in HFpEF, Borlaug et al. estimated the prevalence of ED in HFpEF patients at $42 \%$ [48]. Of note, the cutoff to define ED in this study was arbitrarily chosen as RHI $<2.0$, which is substantially higher than the original reference value defined in coronary artery disease patients (RHI <1.67) [49]. The prevalence of ED found in the Borlaug study could as such be overestimated.

In the largest study to date, measuring endothelial function in 321 Japanese HFpEF patients, Akiyama et al. found that a RHI below the median predicted CV events [47]. For each decrease of 1.0 in RHI, CV risk increased 20\%. The prognostic significance of ED in HFpEF patients was independent of clinical, echocardiographic, and neurohormonal factors. This was later confirmed in a smaller study by Matsue et al. [50]. Of note, both Japanese studies propose a prognostic cutoff value for $\mathrm{RHI}<1.63$, close to the original reference value of RHI <1.67. Applied to the large Akiyama study, this implies an ED prevalence of $50 \%$ in $\mathrm{HFpEF}$ patients. Full details of studies measuring peripheral ED in HFpEF can be found in Table 1.

Given the central role of ED in the development of HFpEF, this estimated prevalence of ED of $42-50 \%$ seems low. However, to be more precise, $42-50 \%$ of HFpEF patients have peripheral ED as defined by a given RHI cutoff. In our opinion, the other $50 \%$ fail to show decreased RHI because of the following reasons. First, it takes time before microvascular inflammation is translated to clinically measureable 


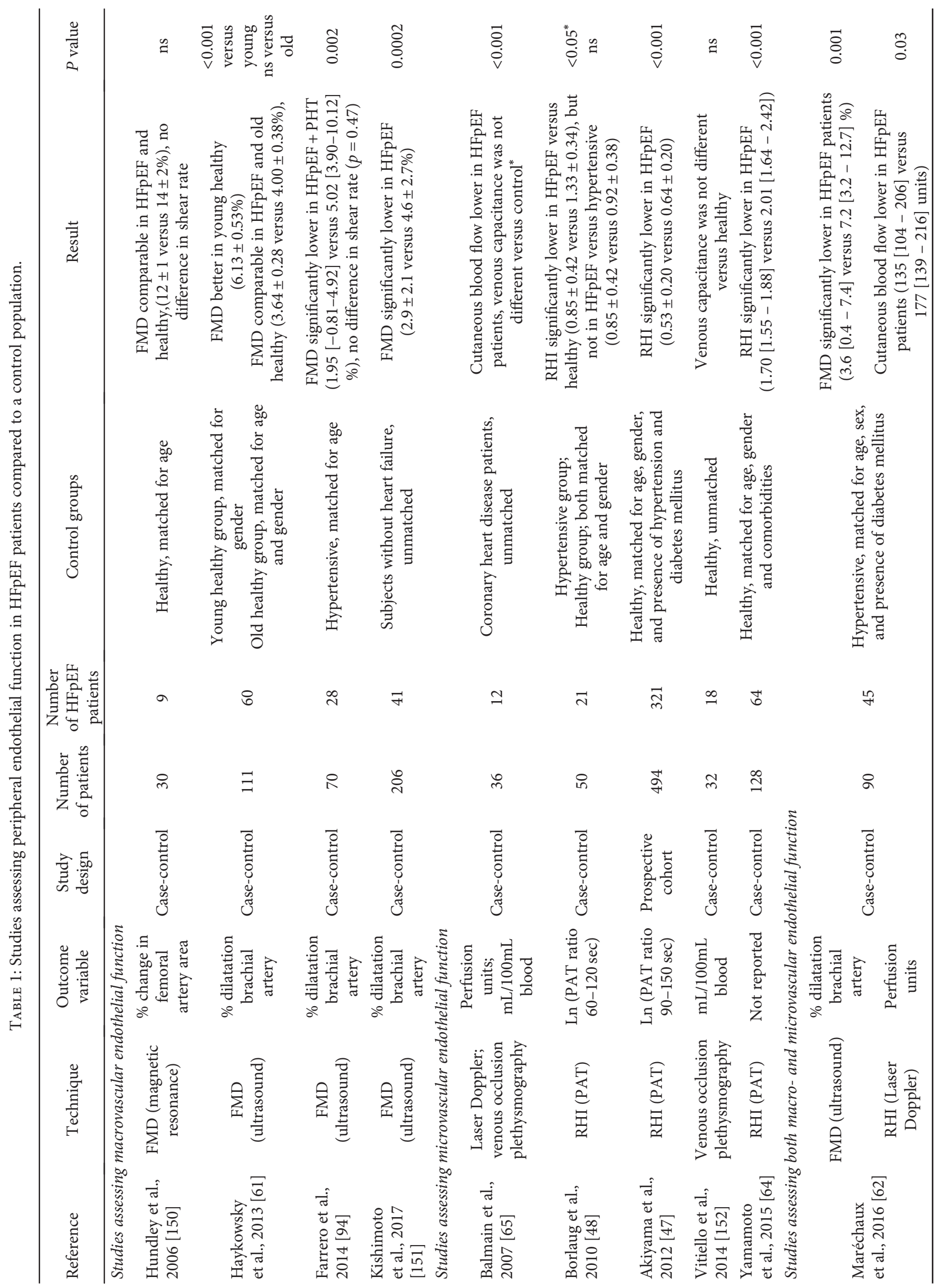




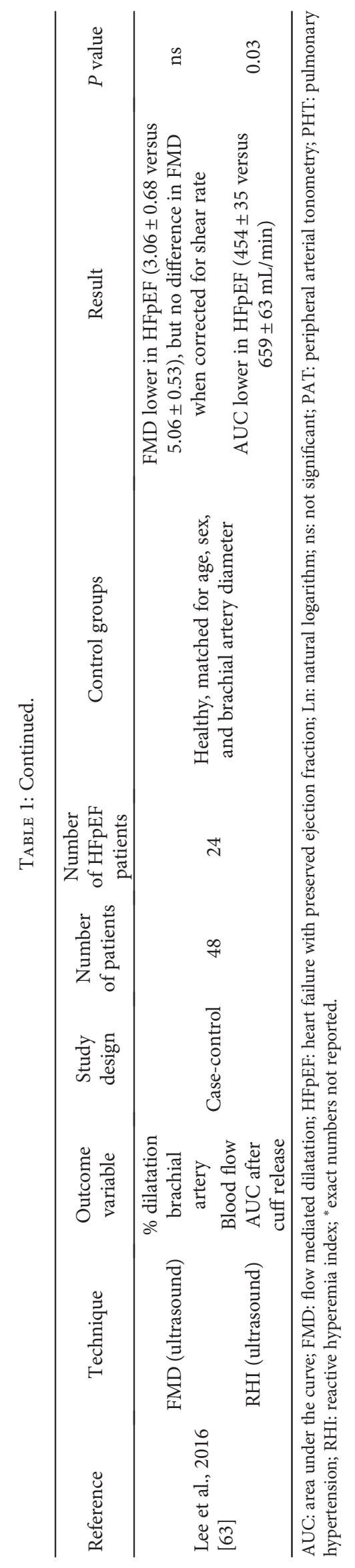


disturbances in vasoreactivity. Second, the cutoff of RHI $<1.63$ reflects a value useful for clinical prognosis, but has not been correlated with pathophysiological changes such as endothelial inflammation and reduced NO bioavailability. Third, RHI and FMD show poor agreement which suggests different mechanisms are measured [51]. Possibly, FMD more accurately reflects reduced NO signaling, but data on FMD in HFpEF is incomplete (no large or prognostic studies), and a cutoff defining ED is not available. Perhaps, it is more correct to state that the prevalence of ED in HFpEF is hard to estimate based on current data, but almost half of patients have reduced peripheral endothelial-dependent vasodilation compared to controls, which is linked to increased CV events.

Another clinical clue to the importance of ED is the relation with exercise intolerance, objectively measured by cardiopulmonary exercise testing and determination of $\mathrm{VO}_{2}$ peak. This is related to adverse prognosis, since $\mathrm{VO}_{2}$ peak is one of the strongest predictors of mortality in HFpEF [52]. The Fick principle $\left(\mathrm{VO}_{2}=\right.$ cardiac output $\bullet$ arteriovenous $\mathrm{O}_{2}$ difference) states that $\mathrm{VO}_{2}$ peak can be limited by either a central factor, cardiac output, or peripheral $\mathrm{O}_{2}$ extraction. The latter is influenced by oxygenation of the blood in the lungs, $\mathrm{O}_{2}$ carrying capacity of the blood, appropriate distribution of blood to the peripheral tissues, and adequate tissue $\mathrm{O}_{2}$ extraction from the blood. A key factor is the oxygen diffusion capacity $\left(\mathrm{DO}_{2}\right)$, which can be a limiting factor in both pulmonary and skeletal muscle $\mathrm{O}_{2}$ kinetics. Applying Fick's law of diffusion $\left(\mathrm{VO}_{2}=\mathrm{DO}_{2} \cdot\right.$ (capillary $\mathrm{pO}_{2}$ - intracellular $\mathrm{pO}_{2}$ ) with $\mathrm{pO}_{2}$ being partial oxygen pressure) in exercising muscle, where intracellular $\mathrm{pO}_{2}$ is very low, the capillary $\mathrm{pO}_{2}$ determines the $\mathrm{O}_{2}$ diffusion gradient. As such, capillary $\mathrm{pO}_{2}$ can limit $\mathrm{VO}_{2}$ during exercise [53]. Adequate endothelial function is necessary for an appropriate exercise-induced increase in blood flow to the muscles [54]. As capillary $\mathrm{pO}_{2}$ is determined by the instantaneous balance between $\mathrm{VO}_{2}$ and perfusion, ED can also limit capillary $\mathrm{pO}_{2}$ [53]. In theory, $\mathrm{ED}$ can thus limit $\mathrm{VO}_{2}$ both by reducing capillary blood flow and limiting $\mathrm{O}_{2}$ diffusion.

Reduced cardiac output on exertion was long considered the main mechanism behind exercise intolerance in HFpEF [55]. Chronotropic incompetence and reduced peak stroke volume have both been implicated as the most important factor limiting $\mathrm{VO}_{2}$ peak [56]. More recently, a peripheral limitation to exercise capacity in HFpEF has been put forward. Borlaug et al. reported reduced systemic vascular resistance and lower RHI at peak exercise in HFpEF patients compared to hypertensive and healthy controls [48]. Haykowsky et al. even suggested that a failure to increase peripheral $\mathrm{O}_{2}$ extraction during exercise is the predominant factor limiting $\mathrm{VO}_{2}$ peak [57]. The rest-to-peak change in peripheral $\mathrm{O}_{2}$ extraction was the strongest independent predictor of $\mathrm{VO}_{2}$ peak in their study. This was later confirmed using exercise hemodynamics and exercise echocardiography $[58,59]$. Although the dominant limiting factor to $\mathrm{VO}_{2}$ peak remains controversial, clearly peripheral elements play a role in determining exercise capacity in HFpEF. We further elaborate this finding in the next section.

\section{Various Vascular Beds Display Endothelial Dysfunction in HFPEF}

Theoretically, many clinical findings related to the HFpEF syndrome could be explained by a system-wide ED, leading to alterations in several organ systems. In Figure 2, we postulate that systemic ED is the underlying pathophysiological mechanism by which HFpEF risk factors lead to exercise intolerance. Systemic inflammation induced by HFpEF risk factors creates oxidative stress at the level of the endothelium throughout the vasculature, reducing NO availability for adjacent cells pertaining to all organs implicated in exercise performance.

In what follows, we review the evidence of the presence, extent, and underlying mechanisms of ED in different vascular beds and the corresponding organs.

6.1. Peripheral Vasculature and Skeletal Muscle. The peripheral circulation is the preferred organ system for measuring endothelial-dependent vasodilation, because of the easy, noninvasive measurement and the good correlation with "gold standard" invasive coronary vasodilation [60]. Studies evaluating peripheral endothelial function in HFpEF are summarized in Table 1.

Evidence regarding macrovascular ED in HFpEF is conflicting. The largest study to date reported no significant difference in FMD between HFpEF patients and healthy volunteers matched for age and gender [61]. In contrast, in almost all studies assessing microvascular peripheral endothelial function through RHI measurement, HFpEF patients have evidence of microvascular ED [48, 62-65]. Also, prognostic significance for ED in HFpEF has only been proven for microvascular dysfunction [47]. Of note, many studies have different methodologies even when using the same technique for measuring endothelial function. Control groups are often heterogeneous and unmatched, few studies using FMD adhere to the most recent guidelines that state shear stimulus must be reported, $[66,67]$ and different cutoffs for identifying $\mathrm{ED}$ are used. These disparities complicate the interpretation of study results.

Besides vasodilatory dysfunction of the afferent arteries to the working muscle, reduced peripheral $\mathrm{O}_{2}$ extraction in HFpEF can also result from skeletal muscle dysfunction. HFpEF patients indeed have abnormalities in skeletal muscle mass, composition, capillary density, and oxidative metabolism. In contrast to the high prevalence of obesity, HFpEF patients have reduced lean leg mass [68]. This could be related to adipose tissue infiltration in muscle, which shows a similar correlation with exercise capacity. A markedly lower $\mathrm{VO}_{2}$ peak indexed to lean body mass in HFpEF patients further confirms that abnormalities in skeletal muscle perfusion and/or metabolism contribute to exercise intolerance [69]. Mitochondria are important regulators of skeletal muscle metabolism. Recently, reductions in muscle mitochondrial content, oxidative capacity, and expression of key mitochondrial proteins were found in muscle biopsies of HFpEF patients [70]. These changes were related to $\mathrm{VO}_{2}$ peak, emphasizing muscle mitochondrial dysfunction is likely a limiting factor to exercise 


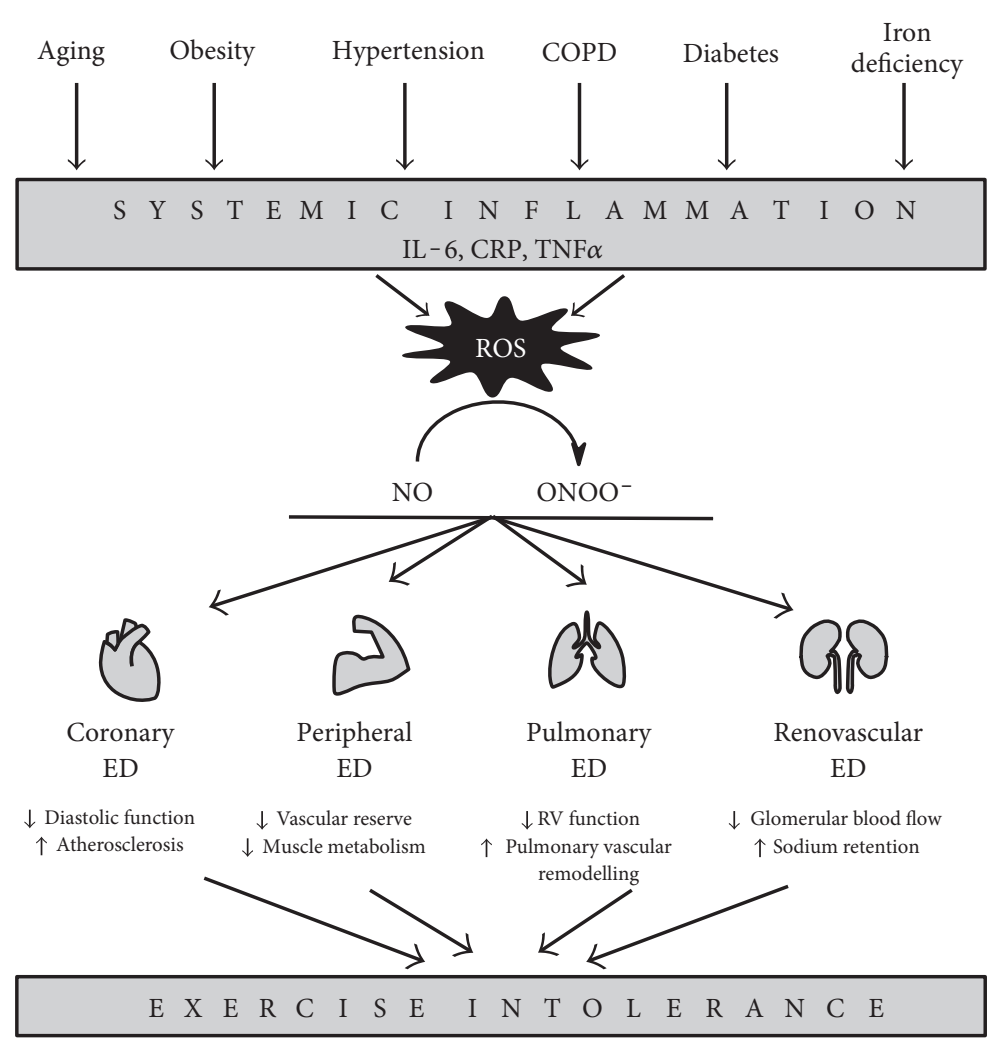

FIgURE 2: Role of system-wide endothelial dysfunction in HFpEF pathophysiology. Comorbidities induce systemic inflammation, creating

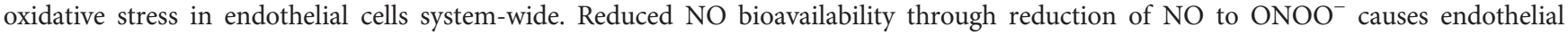
dysfunction. In different vascular beds, endothelial dysfunction has heterogeneous effects, which manifest as the cardinal HFpEF symptom of exercise intolerance. $\mathrm{COPD}=$ chronic obstructive pulmonary disease, $\mathrm{CRP}=\mathrm{C}$-reactive protein, $\mathrm{ED}=\mathrm{endothelial}$ dysfunction, IL-6=interleukin-6, $\mathrm{NO}=$ nitric oxide, $\mathrm{ONOO}^{-}=$peroxynitrite, $\mathrm{ROS}=$ reactive oxygen species, $\mathrm{RV}=$ right ventricle, TNF $\alpha=$ tumor necrosis factor alpha.

capacity. Other possible underlying molecular changes could be a switch from oxidative slow-twitch type I fibers to glycolytic fast-twitch type II fibers which reduces oxidative capacity, increased muscle fatigability, and a reduction in skeletal muscle capillary density [71].

The latter is especially intriguing, as it links these skeletal muscle abnormalities to vascular dysfunction. Kitzman et al. demonstrated a severely reduced capillary-to-fiber ratio in muscles of $\mathrm{HFpEF}$ patients, related to $\mathrm{VO}_{2}$ peak [72]. A lower capillary density, and hence reduced capillary blood supply, may also underlie the muscle fiber atrophy seen in animal and human HFpEF studies [69, 71]. Also, as muscle blood flow assumes an important role in limiting $\mathrm{VO}_{2}$ kinetics, the authors suggest a decreased $\mathrm{O}_{2}$ diffusion to contracting muscle limits exercise capacity in HFpEF. As mentioned above, ED could play a role in this limitation of diffusive capacity by reducing the $\mathrm{pO}_{2}$ driving gradient.

When leg blood flow is measured by ultrasound Doppler, HFpEF patients indeed have a reduced muscle blood flow during exercise compared to healthy controls, even at relatively low workloads of 10-15 W [73]. Stroke volume and heart rate were similar in HFpEF and control patients in this study, again implying a vascular (and not cardiac) limitation of exercise capacity. Also, HFpEF patients fail to augment peripheral $\mathrm{O}_{2}$ extraction during exercise with a greater increase in blood pressure than controls [59]. This suggests that a reduced vasodilatory capacity prevents appropriate distribution of blood flow during exercise, leading to limitation of exercise capacity [55]. Possibly, microvascular ED contributes more than macrovascular ED at the level of the muscle vascular bed, as Haykowsky et al. found a peripheral limitation of exercise capacity but no decrease in FMD $[61,74]$.

In summary, there is evidence for microvascular ED in HFpEF, predictive of long-term CV morbidity. Reports on macrovascular dysfunction are conflicting, and all studies suffer from methodological disparities. Also, HFpEF patients suffer numerous changes in skeletal muscles which correlate with reduced $\mathrm{VO}_{2}$ peak, including mitochondrial dysfunction, fiber atrophy, and reduced oxidative capacity. Possibly, skeletal muscle abnormalities are linked to vascular dysfunction through a reduction in muscle capillary density, which limits muscle blood flow and $\mathrm{O}_{2}$ diffusion during exercise.

6.2. Heart. Traditionally, coronary endothelial function is measured by intracoronary infusion of a vasodilating substance such as acetylcholine. Subsequently, microvascular function can be estimated by measuring coronary flow reserve (CFR), the ratio of coronary blood flow after the vasodilating stimulus over blood flow at rest. In HFrEF 
patients, CFR correlates with $\mathrm{VO}_{2}$ peak, invasive and echocardiographic hemodynamics, and mortality [75-77]. Tschöpe et al. measured CFR in patients with diastolic dysfunction, showing a reduced vasodilatory response to intracoronary acetylcholine infusion even before onset of HF symptoms [78]. Furthermore, invasively measured CFR is reduced in HFpEF patients and CFR correlates with echocardiographic measures of diastolic function and LV hypertrophy $[76,78,79]$. Interestingly, two studies in HFrEF patients showed no relationship between CFR and peripheral endothelial function $[75,80]$. As such, different pathophysiological mechanisms may lie at the origin of coronary and peripheral ED.

As mentioned above, reduced NO bioavailability leads to both structural and functional changes in HFpEF. Structurally, HFpEF hearts are characterized by interstitial fibrosis and both macroscopic and microscopic hypertrophy [10]. Hemodynamically, diastolic dysfunction is evident as slowed ventricular relaxation on one hand and decreased compliance due to myocardial stiffness on the other hand [9].

In the normal heart, endothelial NO bursts directly modulate relaxation in a beat-to-beat way [81]. High levels of peroxynitrite $\left(\mathrm{ONOO}^{-}\right)$, however, increase diastolic calcium content and thus delay cardiomyocyte relaxation [82]. Through its effects on sGC, NO is also able to modify cardiomyocyte stiffness and hypertrophy. sGC increases cGMP production, which in turn increases cellular PKG content. PKG acutely reduces cardiomyocyte stiffness through phosphorylation of the giant protein titin, the most important regulator of passive myocardial stiffness. Also, PKG functions as a brake on several pathways implicated in left ventricular hypertrophy. The sGC-cGMP-PKG pathway and its targets are indeed downregulated in HFpEF animals $[83,84]$. Low PKG content has also been found in myocardial biopsies from HFpEF patients [41].

Finally, NO exerts direct antifibrotic effects in the heart by counteracting endothelin-1, angiotensin II, and aldosterone. Reduced NO bioavailability leaves profibrotic actions of these molecules unopposed, promoting proliferation of fibroblasts and myofibroblasts [85].

In summary, microvascular cardiac endothelium modulates diastolic function and development of LV hypertrophy and fibrosis. Coronary microvascular function, as measured by CFR, is reduced in $\mathrm{HFpEF}$ but does not relate to peripheral ED.

6.3. Lungs. Pulmonary hypertension (PHT) at rest is highly prevalent in HFpEF patients, with up to $83 \%$ affected [86]. Patients often have an exaggerated elevation of pulmonary artery pressures during exercise $[87,88]$. This increased afterload on the right ventricle (RV) and the presence of common risk factors explain the high prevalence of RV dysfunction in $\mathrm{HFpEF}$, which is associated with increased morbidity and mortality [89].

Passive transition of elevated end-diastolic pressure explains only part of the elevated pulmonary artery pressures in HFpEF [86]. As in patients with HFrEF and pulmonary arterial hypertension, impaired NO-dependent pulmonary vasodilation has been described in HFpEF patients. The Mayo Clinic group has spearheaded research in this field, proving abnormal RV and pulmonary artery hemodynamics both at rest and on exertion [88]. Although initially an increased pulmonary vasodilatory capacity was suggested based on dobutamine infusion [90], recent invasive measurements showed reduced exercise-induced pulmonary vasodilation in HFpEF [88].

Pulmonary arterial endothelial function was disturbed, and pulmonary artery pressures were higher in an animal infarct model of HFpEF, while aortic endothelial function and intracardiac pressures remained unaltered [91]. This could mean that pulmonary vascular ED even precedes systemic ED in HFpEF. Indeed, as the pulmonary circulation is primarily flow-driven in contrast to the pressure-driven systemic circulation, it may be more susceptible to the influence of shear stress and ED [92]. More recently, a murine model of HFpEF with PHT was established by blocking vascular endothelial growth factor receptors in obese and hypertensive rats. Oral administration of nitrite, which acts as NO donor, prevented the development of PHT but could not reverse established PHT [93]. These findings are compatible with "reversible" pulmonary ED playing an early role in the establishment of PHT, while "fixed"vascular remodeling occurs in more advanced stages.

In a cohort of $28 \mathrm{HFpEF}$ patients with $\mathrm{PHT}$ that had severe macrovascular ED (FMD median 1.95\%), Farrero et al. found a significant inverse correlation between FMD and pulmonary vascular resistance. No correlation was found with capillary wedge pressure [94]. While this does not prove a causal relationship, it is plausible that more severe HFpEF is related with more severe ED in the systemic and pulmonary vasculature, ultimately leading to PHT. This would corroborate the concept of whole-body ED in HFpEF.

$\mathrm{PHT}$ is also induced through reactive pulmonary vasoconstriction and vascular remodeling [95]. This process is largely mediated by $\mathrm{NO}$, as pulmonary vascular reactivity is maintained by continuous local NO production [95]. A systemic reduced NO bioavailability, as found in HFpEF, causes vascular smooth muscle dysfunction in the pulmonary vasculature, paving the way for PHT [96].

Pulmonary function itself is frequently disturbed in HFpEF patients, with 59\% suffering airflow limitation on spirometry [97]. As pulmonary impairment increases with symptom severity, pulmonary edema is a likely explanation. But diaphragm dysfunction may also contribute by increasing work of breathing. The diaphragm exhibits similar changes as skeletal muscle in HFpEF, including fiber atrophy, decreased oxidative capacity, impaired mitochondrial function, and increased fatigability [71]. As ED possibly underlies several skeletal muscle alterations, ED could also be a pathophysiological factor in diaphragm dysfunction, forming the link between skeletal muscle and respiratory abnormalities in HFpEF.

Pulmonary gas exchange is impaired in up to $83 \%$ of HFpEF patients, showing true $\mathrm{O}_{2}$ diffusion limitation at rest in 59\% [97]. At exercise, diffusion abnormalities are exacerbated in HFpEF patients compared to healthy individuals [98]. These findings provide further evidence that exercise 
capacity is limited by $\mathrm{O}_{2}$ diffusion in both the systemic and the pulmonary microcirculation.

In summary, PHT is a frequent and ominous finding in HFpEF patients. Vascular remodeling and reactive pulmonary vasoconstriction, caused by a reduced systemic NO bioavailability, play an important role in its development. Spirometry, diaphragm function, and pulmonary diffusion capacity are frequently impaired in HFpEF patients. Possibly, ED plays a role by impairing $\mathrm{O}_{2}$ diffusion in the pulmonary microcirculation and causing adverse changes in diaphragm muscle composition similar to those in skeletal muscle.

6.4. Kidneys. HFpEF can induce renal dysfunction, and vice versa. Chronic kidney disease is highly prevalent in HFpEF patients (30-34\% in large outcome trials) $[99,100]$. Moreover, HF mortality is increased by concurrent renal impairment [101].

Clinically, endothelial function is impaired in patients with even mild chronic kidney disease, whether measured by RHI or FMD [102, 103]. Furthermore, worse endothelial function correlates with worse diastolic function on echocardiography [104]. Studies on the impact of renal disease on progression of ED in HFpEF are currently still lacking, but it is certainly an interesting field for future research [105].

HFpEF can cause renal dysfunction in different ways [106]. First, hemodynamic factors impair glomerular blood flow. Renal congestion due to elevated central venous pressure increases efferent glomerular pressure [107]. Additionally, fixed stroke volume and chronotropic incompetence reduce cardiac output on exertion, which impairs afferent blood flow [108]. The net result is decreased glomerular blood flow, leading to renovascular and glomerular injury and activating sodium retention pathways [109]. Second, the systemic inflammation that accompanies HFpEF has deleterious effects on the kidneys. Leukocyte recruitment causes renal fibrosis through transforming growth factor $\beta$-mediated fibroblast stimulation. Also, systemic inflammation reduces NO bioavailability as described above. Renal blood flow is dependent on systemic NO supply, which is reduced in HFpEF [110]. In a metabolic syndrome rat model of HFpEF, degradation of peritubular and glomerular microvasculature is linked with progressive glomerulosclerosis [111]. Interestingly, in this last study, microscopic renal damage was evident before onset of HFpEF.

On the other hand, renal disease can also lead to HFpEF. In long-term follow-up of $>8500$ chronic kidney disease patients, 34\% was diagnosed with new-onset HFpEF [112]. Possible mechanisms include, again, worsening endothelial function and inducing systemic inflammation [105]. Several important feedback mechanisms, regulated by the kidney and disturbed in renal failure, induce ED: vitamin D deficiency, erythropoietin deficiency, elevated parathyroid hormone levels, and phosphorus excess [113-115]. Also, the endothelium is involved in sodium handling. Sodium retention could increase intracellular sodium, which disrupts endothelial homeostasis [116]. Asymmetric dimethyl arginine, a retention product found in kidney failure, is a competitive inhibitor of eNOS and increases endothelial oxidative stress [106].

In summary, $\mathrm{HFpEF}$ and chronic kidney disease are mutually influencing conditions. ED is an important risk factor for both diseases, and interesting pathophysiological links exist.

\section{Exercise Training: The Silver Lining on the Cloud}

Cardiac rehabilitation programs have been a mainstay of $\mathrm{HFrEF}$ treatment after it was discovered that training is safe and reduces hospitalizations [21]. The evidence in HFpEF, however, is still emerging. Several medium-sized singlecenter studies demonstrated substantial benefit of training in HFpEF patients [117-122]. Three recent meta-analyses concluded that exercise training in $\mathrm{HFpEF}$ increases $\mathrm{VO}_{2}$ peak and physical function scores [123-125]. Diastolic function (measured by E/e' ratio and left atrial volume) also improved with exercise in the landmark Ex-DHF trial [117]. These results have led to a class I, level of evidence A recommendation for exercise training in HF patients regardless of their ejection fraction in recent European Society of Cardiology HF guidelines [2]. Although no recommendations are made towards the intensity of exercise training, existing evidence suggests diverging effects of standard moderate-intensity aerobic training (at $60-70 \%$ of $\mathrm{VO}_{2}$ peak) and high intensity interval training (adding short intervals at $80-90 \% \mathrm{VO}_{2}$ peak). In a single-center trial, high intensity training in HFrEF patients led to superior increases in $\mathrm{VO}_{2}$ peak and ejection fraction compared to moderate training [126]. Unfortunately, these findings could not be replicated in the large multicenter SmartEx trial [127]. Of note, the majority of patients exercised below the prescribed target in the high-intensity group and above target in the moderate group. A pilot study in $15 \mathrm{HFpEF}$ patients showed superior effects of high intensity interval training on exercise capacity and diastolic function [128]. However, the lack of $\mathrm{VO}_{2}$ peak improvement in patients training at moderate intensity contrasts with the earlier studies.

The ongoing OptimEx study aims to study optimal exercise dose in $180 \mathrm{HFpEF}$ patients with regard to aerobic capacity [129]. Also, this trial will reevaluate the effect of exercise training on FMD in HFpEF patients and add much-needed information on microvascular function.

In the contemporary "whole-systems" approach towards HFpEF therapy, ED forms an attractive target due to its systemic nature and reversibility in early stages. Improving ED in HFpEF can be achieved through correction of comorbidities, increasing NO bioavailability, or antioxidative therapy. Sadly, none of these approaches alone has thus far been successful in decreasing HFpEF-related morbidity or mortality. Exercise training integrates all three mechanisms, forming a promising systemically oriented therapy [7].

Both peripheral endothelial function and muscle metabolism are beneficially influenced by exercise. Exercise increases NO production by upregulating and phosphorylating eNOS through increased shear stress and vascular endothelial growth factor 2 release [19]. Exercise training also 
reduces oxidative stress by downregulating angiotensin receptors and nicotinamide adenine dinucleotide phosphate oxidase [130]. In addition, the anti-inflammatory and permeability decreasing properties of exercise may contribute to improvement of endothelial function [22].

Circulating progenitor cells could add to these favorable changes [131]. Endothelium-repairing endothelial progenitor cells are mobilized from the bone marrow by stimuli such as ischemia and cytokine release, under control of circulating angiogenic T lymphocytes [132, 133]. Our group has shown that the number of circulating angiogenic $T$ lymphocytes and their functional capacity increase with exercise training, both in healthy subjects and HF patients [134]. The acute exerciseinduced changes in circulating angiogenic $\mathrm{T}$ lymphocyte function wane with exercise training, suggesting that repetitive exercise bouts progressively lead to endothelial repair [135]. Another group has recently shown increases in endothelial progenitor cell number and function in HF patients as well [136].

Molecular determinants of exercise-induced effects specific to HFpEF are still poorly investigated. In HFpEF rats, exercise training restored endothelial-dependent vasodilation measured ex vivo in organ baths [40]. Endothelial function correlated well with eNOS expression, which was reduced in HFpEF rats and recovered after exercise training. Matrix metalloproteinase activity, which is an indirect measure of extracellular matrix degradation and thus vessel wall modulation, was increased in HFpEF and blunted by exercise training while the endothelial cell layer remained intact. This suggests exercise-induced vascular changes extend beyond the endothelium.

In a secondary analysis of the Ex-DHF trial, circulating cytokines and hormones were analyzed in HFpEF patients before and after training [137]. Inflammatory cytokines (interleukins $1 \beta, 6$, and 10 and tumor necrosis factor alpha) showed no change with exercise. Interestingly, levels of the growth hormone releasing peptide ghrelin, which inhibits cardiomyocyte and endothelial cell apoptosis in vitro, increased by exercise training. Clearly, molecular determinants underlying the exercise-induced benefits in HFpEF deserve further in-depth exploration.

Clinically, peripheral endothelial function shows improvement after exercise training in patients with $\mathrm{CV}$ risk factors, coronary atherosclerosis, and HFrEF [138-140]. Of note, when comparing high intensity interval training to moderate training in HFrEF, endothelial function (as measured by FMD) and mitochondrial function (determined from muscle biopsies) improved only by high intensity training [126]. In HFpEF patients, Haykowsky et al. found that exercise training can increase peripheral $\mathrm{O}_{2}$ extraction. The increase in $\mathrm{VO}_{2}$ peak was almost entirely attributable to an improvement in peripheral function (i.e., improved vascular and/or skeletal muscle functions) [141]. In a study by $\mathrm{Fu}$ et al., aerobic interval training increased muscle perfusion and muscle $\mathrm{O}_{2}$ extraction in HFpEF patients. This increase in muscle vascular function was the only significant predictor of $\mathrm{VO}_{2}$ peak. Interestingly, this phenomenon was not seen in HFrEF patients, for whom improved cardiac output was the only predictor of $\mathrm{VO}_{2}$ peak [142].
Conversely, Kitzman et al. could not demonstrate an improvement of FMD after training HFpEF patients, despite an increase in $\mathrm{VO}_{2}$ peak [74]. A possible confounder could be that FMD was measured in the postprandial state in the Kitzman study, while guidelines advise to assess FMD in a fasting state because of a significant influence of food ingestion $[67,143]$. In addition, the intensity of the exercise training protocol in this study was rather moderate and therefore could have failed to induce changes in macrovascular endothelial function.

There is no data regarding the effects of training on coronary, pulmonary, or renal ED in HFpEF patients. However, studies in patients with other CV diseases suggest exercise training is indeed able to improve regional endothelial function. Coronary endothelial function is improved by cardiac rehabilitation in dilated cardiomyopathy and coronary atherosclerosis $[138,144]$. In patients with chronic kidney disease, changes in several molecular markers (asymmetric dimethyl arginine, glutathione, and lipid peroxidation products) suggest increased NO bioavailability through exercise training [106]. Unfortunately, Van Craenenbroeck et al. found that exercise training did not improve FMD nor cellular markers of vascular function, despite an increase in $\mathrm{VO}_{2}$ peak [102]. However, data on microvascular function is lacking.

\section{Future Directions}

Considering HFpEF as a multisystem syndrome rather than an isolated cardiac disease could lead us to alternative research approaches and eventually to successful therapies. The heterogeneity of the HFpEF patient population has frequently been cited as one of the reasons major trials have failed to prove a benefit for pharmacological treatment [145]. Efforts to subdivide HFpEF patients into different phenotypes have only started recently [146-148]. In the spectrum of HFpEF as a multisystem pathology, some patients seem younger and suffer less cardiac impairment, some have important metabolic disorders and more severe cardiac disease including RV and pulmonary vascular involvement, and others have a predominant renal dysfunction. Importantly, prognosis between phenotypes differs substantially [147]. The greatest challenges for future HFpEF research will be to correctly stratify patients into phenogroups and to design clinical trials accordingly. Whether endothelial function measurement could aid in identifying the correct HFpEF phenotype in patients is still unknown.

Also, a one-size-fits-all therapeutic approach is probably not the best strategy for the heterogeneous HFpEF population. A treatment algorithm based on presence of different comorbidities has recently been proposed [146]. Keeping in mind the important effects of even low-level exercise, matching or stratifying groups for physical activity seems reasonable when designing HFpEF trials, although maintaining statistical power will require a delicate balance. Rather, we support further subdividing of HFpEF based on large phenotyping studies to better characterize this heterogeneous population. Clinical trials could then be focused on a well-defined subgroup, eliminating confounding by other phenotypes. 


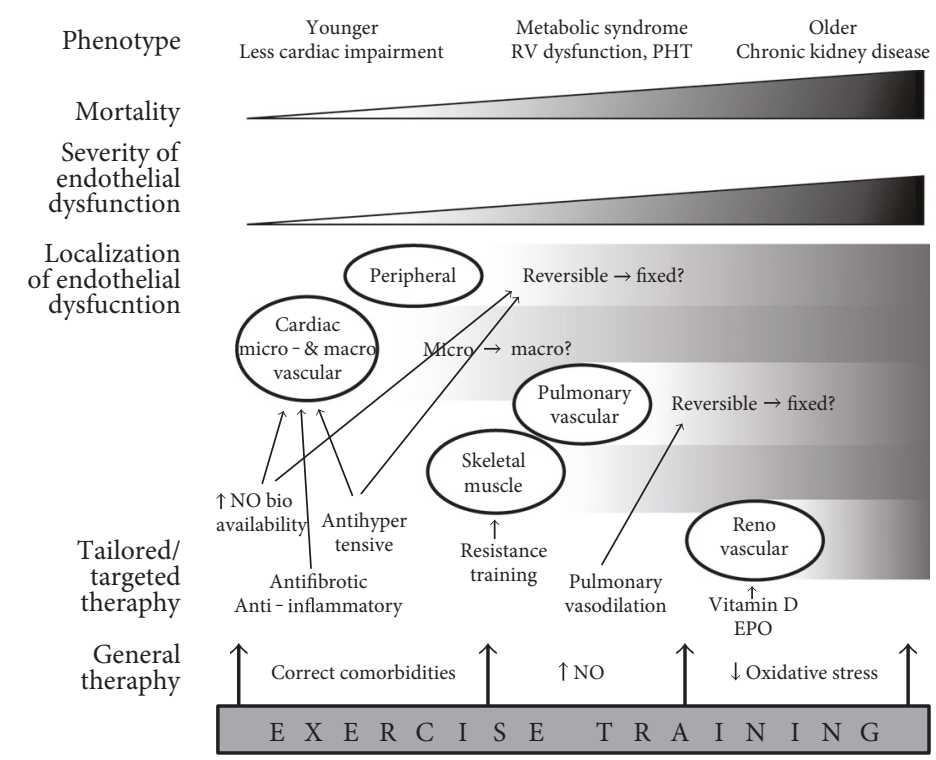

FIgURE 3: Possibilities for exercise training and targeted therapies depending on HFpEF phenotype. Cardiac ED is an early hallmark in all HFpEF patients. In older patients, pulmonary and renal vasculature are more frequently involved, and mortality is higher. HFpEF therapy could be tailored for each phenotype. Younger patients could still benefit from correction of comorbidities, preventing further systemic inflammation and ED. Increasing NO bioavailability, antifibrotic, or anti-inflammatory therapy could also be useful in early stages. Pulmonary vasodilation can only be effective when pulmonary vascular ED is manifested and still reversible. Exercise training has possible benefits at each stage, as it is able to correct comorbidities (weight loss, better glycemic control), increase NO bioavailability, and reduce systemic oxidative stress. $\mathrm{EPO}=$ erythropoietin, $\mathrm{NO}=$ nitric oxide, $\mathrm{PHT}=$ pulmonary hypertension, $\mathrm{RV}=$ right ventricle.

Unravelling the beneficial effects of exercise training in HFpEF could lead to patient-specific new therapies. Such a tailored approach can be useful in patients who are unable to exercise, or as add-on to a training program. Pharmacological or nonpharmacological correction of comorbidities, increase of NO bioavailability, and antioxidative therapy are possible targets, some of which are being explored in clinical trials already $[119,149]$. These can be combined with exercise training to compose a truly personalized treatment for each patient (Figure 3).

\section{Conclusions}

$\mathrm{HFpEF}$ is a multisystem pathology. Cardiac dysfunction is not the sole causative factor, but interacts with a heterogeneous range of organ dysfunctions, including pulmonary, renal, peripheral vascular, and skeletal muscle dysfunctions. Endothelial dysfunction could be a central mechanism in this system-wide CV maladaptation, as such it forms an attractive target for future HFpEF therapies. Exercise training is thus far the only therapy with proven beneficial effects in HFpEF. While exercise training does not improve macrovascular $\mathrm{ED}$ in $\mathrm{HFpEF}$, evidence does suggest peripheral vascular and/or skeletal muscle function is enhanced. This warrants a shift in both fundamental and clinical research towards endothelial-targeted therapies, including exercise training, in the search for an effective therapeutic strategy for HFpEF.

\section{Conflicts of Interest}

The authors declare that they have no conflicts of interest.

\section{Funding}

EMVC is supported by the fund for scientific researchFlanders (FWO) as Senior clinical investigator. Research Group Cardiovascular Diseases is part of the Infla-Med Research Consortium of Excellence.

\section{References}

[1] V. L. Roger, "Epidemiology of heart failure," Circulation Research, vol. 113, no. 6, pp. 646-660, 2013.

[2] P. Ponikowski, A. A. Voors, S. D. Anker et al., "2016 ESC guidelines for the diagnosis and treatment of acute and chronic heart failure," European Heart Journal, vol. 37, no. 27, pp. 2129-2200, 2016.

[3] S. Yusuf, M. A. Pfeffer, K. Swedberg et al., "Effects of candesartan in patients with chronic heart failure and preserved left-ventricular ejection fraction: the CHARM-preserved trial," Lancet, vol. 362, no. 9386, pp. 777-781, 2003.

[4] B. Pitt, M. A. Pfeffer, S. F. Assmann et al., "Spironolactone for heart failure with preserved ejection fraction," The New England Journal of Medicine, vol. 370, no. 15, pp. 13831392, 2014.

[5] V. M. Conraads, M. Metra, O. Kamp et al., "Effects of the long-term administration of nebivolol on the clinical symptoms, exercise capacity, and left ventricular function of patients with diastolic dysfunction: results of the ELANDD study," European Journal of Heart Failure, vol. 14, no. 2, pp. 219-225, 2012.

[6] S. L. Lim, C. S. P. Lam, V. F. M. Segers, D. L. Brutsaert, and G. W. De Keulenaer, "Cardiac endothelium-myocyte interaction: clinical opportunities for new heart failure therapies 
regardless of ejection fraction," European Heart Journal, vol. 36, no. 31, pp. 2050-2060, 2015.

[7] G. W. De Keulenaer, V. F. M. Segers, F. Zannad, and D. L. Brutsaert, "The future of pleiotropic therapy in heart failure. Lessons from the benefits of exercise training on endothelial function," European Journal of Heart Failure, vol. 19, pp. 603-614, 2017.

[8] R. S. Bhatia, J. V. Tu, D. S. Lee et al., "Outcome of heart failure with preserved ejection fraction in a population-based study," The New England Journal of Medicine, vol. 355, no. 3, pp. 260-269, 2006.

[9] B. A. Borlaug, "The pathophysiology of heart failure with preserved ejection fraction," Nature Reviews. Cardiology, vol. 11, no. 10, pp. 507-515, 2014.

[10] W. J. Paulus and C. Tschöpe, "A novel paradigm for heart failure with preserved ejection fraction," Journal of the American College of Cardiology, vol. 62, no. 4, pp. 263-271, 2013.

[11] D. L. Brutsaert and S. U. Sys, "Relaxation and diastole of the heart," Physiological Reviews, vol. 69, no. 4, pp. 1228-1315, 1989.

[12] M. E. Widlansky, N. Gokce, J. F. Keaney, and J. Vita, “A. The clinical implications of endothelial dysfunction," Journal of the American College of Cardiology, vol. 42, no. 7, pp. 11491160, 2003.

[13] Y. Xu, R. C. Arora, B. M. Hiebert et al., "Non-invasive endothelial function testing and the risk of adverse outcomes: a systematic review and meta-analysis," European Heart Journal. Cardiovascular Imaging, vol. 15, no. 7, pp. 736746, 2014.

[14] S. D. Katz, K. Hryniewicz, I. Hriljac et al., "Vascular endothelial dysfunction and mortality risk in patients with chronic heart failure," Circulation, vol. 111, no. 3, pp. 310-314, 2005.

[15] M. J. Haykowsky, C. R. Tomczak, J. M. Scott, D. I. Paterson, and D. W. Kitzman, "Determinants of exercise intolerance in patients with heart failure and reduced or preserved ejection fraction," Journal of Applied Physiology, vol. 119, no. 6, pp. 739-744, 2015.

[16] B. Upadhya, M. J. Haykowsky, J. Eggebeen, and D. W. Kitzman, "Exercise intolerance in heart failure with preserved ejection fraction: more than a heart problem," Journal of Geriatric Cardiology, vol. 12, no. 3, pp. 294-304, 2015.

[17] D. S. Celermajer, "Endothelial dysfunction: does it matter? Is it reversible?" Journal of the American College of Cardiology, vol. 30, no. 2, pp. 325-333, 1997.

[18] R. Hambrecht, S. Gielen, A. Linke et al., "Effects of exercise training on left ventricular function and peripheral resistance in patients with chronic heart failure," Journal of the American Medical Association, vol. 283, no. 23, pp. 3095-3101, 2000.

[19] R. Hambrecht, E. Fiehn, C. Weigl et al., "Regular physical exercise corrects endothelial dysfunction and improves exercise capacity in patients with chronic heart failure," Circulation, vol. 98, no. 24, pp. 2709-2715, 1998.

[20] R. S. Taylor, A. Brown, S. Ebrahim et al., "Exercise-based rehabilitation for patients with coronary heart disease: systematic review and meta-analysis of randomized controlled trials," The American Journal of Medicine, vol. 116, no. 10, pp. 682-692, 2004.

[21] C. O'Connor, D. Whellan, K. Lee et al., "Efficacy and safety of exercise training in patients with chronic heart failure: HF-ACTION randomized controlled trial," Journal of the American Medical Association, vol. 301, no. 14, pp. 1439-1450, 2009.

[22] S. Gielen, G. Schuler, and V. Adams, "Cardiovascular effects of exercise training: molecular mechanisms," Circulation, vol. 122, no. 12, pp. 1221-1238, 2010.

[23] P. Pacher, J. S. Beckman, and L. Liaudet, "Nitric oxide and peroxynitrite in health and disease," Physiological Reviews, vol. 87, no. 1, pp. 315-424, 2007.

[24] D. L. Brutsaert, "Cardiac endothelial-myocardial signaling: its role in cardiac growth, contractile performance, and rhythmicity," Physiological Reviews, vol. 83, no. 1, pp. 59-115, 2003.

[25] B. Özüyaman, P. Ebner, U. Niesler et al., "Nitric oxide differentially regulates proliferation and mobilization of endothelial progenitor cells but not of hematopoietic stem cells," Thrombosis and Haemostasis, vol. 94, no. 4, pp. 770-772, 2005.

[26] L. Bruyndonckx, V. Y. Hoymans, A. H. Van Craenenbroeck et al., "Assessment of endothelial dysfunction in childhood obesity and clinical use," Oxidative Medicine and Cellular Longevity, vol. 2013, Article ID 174782, 19 pages, 2013.

[27] L. Bruyndonckx, V. Y. Hoymans, K. Lemmens, J. Ramet, and C. J. Vrints, "Childhood obesity-related endothelial dysfunction: an update on pathophysiological mechanisms and diagnostic advancements," Pediatric Research, vol. 79, no. 6, pp. 831-837, 2016.

[28] E. M. Van Craenenbroeck and V. M. Conraads, "Endothelial progenitor cells in vascular health: focus on lifestyle," Microvascular Research, vol. 79, no. 3, pp. 184192, 2010.

[29] E. M. Van Craenenbroeck, A. H. Van Craenenbroeck, S. van Ierssel et al., "Quantification of circulating $\mathrm{CD} 34^{+} / \mathrm{KDR}^{+} /$ $\mathrm{CD} 45^{\mathrm{dim}}$ endothelial progenitor cells: analytical considerations," International Journal of Cardiology, vol. 167, no. 5, pp. 1688-1695, 2013.

[30] D. Fischer, S. Rossa, U. Landmesser et al., "Endothelial dysfunction in patients with chronic heart failure is independently associated with increased incidence of hospitalization, cardiac transplantation, or death," European Heart Journal, vol. 26, no. 1, pp. 65-69, 2005.

[31] A. L. Moens, I. Goovaerts, M. J. Claeys, and C. J. Vrints, "Flow-mediated vasodilation: a diagnostic instrument, or an experimental tool?” Chest, vol. 127, no. 6, pp. 2254-2263, 2005.

[32] L. Bruyndonckx, T. Radtke, P. Eser et al., "Methodological considerations and practical recommendations for the application of peripheral arterial tonometry in children and adolescents," International Journal of Cardiology, vol. 168, no. 4, pp. 3183-3190, 2013.

[33] A. L. Arrebola-Moreno, M. Laclaustra, and J. C. Kaski, "Noninvasive assessment of endothelial function in clinical practice," Revista Española de Cardiología (English Edition), vol. 65, no. 1, pp. 80-90, 2012.

[34] N. M. Hamburg and E. J. Benjamin, "Assessment of endothelial function using digital pulse amplitude tonometry," Trends in Cardiovascular Medicine, vol. 19, no. 1, pp. 6-11, 2009.

[35] C. B. Treasure, J. A. Vita, D. A. Cox et al., "Endotheliumdependent dilation of the coronary microvasculature is impaired in dilated cardiomyopathy," Circulation, vol. 81, no. 3, pp. $772-779,1990$. 
[36] P. Collier, C. J. Watson, V. Voon et al., "Can emerging biomarkers of myocardial remodelling identify asymptomatic hypertensive patients at risk for diastolic dysfunction and diastolic heart failure?" European Journal of Heart Failure, vol. 13, no. 10, pp. 1087-1095, 2011.

[37] A. Kalogeropoulos, V. Georgiopoulou, B. M. Psaty et al., "Inflammatory markers and incident heart failure risk in older adults. The health ABC (health, aging, and body composition) study," Journal of the American College of Cardiology, vol. 55, no. 19, pp. 2129-2137, 2010.

[38] C. Franssen, S. Chen, A. Unger et al., "Myocardial microvascular inflammatory endothelial activation in heart failure with preserved ejection fraction," JACC: Heart Failure, vol. 4, no. 4, pp. 312-324, 2016.

[39] D. Westermann, D. Lindner, M. Kasner et al., "Cardiac inflammation contributes to changes in the extracellular matrix in patients with heart failure and normal ejection fraction," Circulation: Heart Failure, vol. 4, no. 1, pp. 44-52, 2011.

[40] V. Adams, M. Alves, T. Fischer et al., "High-intensity interval training attenuates endothelial dysfunction in a dahl saltsensitive rat model of heart failure with preserved ejection fraction," Journal of Applied Physiology, vol. 119, no. 6, pp. 745-752, 2015.

[41] L. Van Heerebeek, N. Hamdani, I. Falcão-Pires et al., "Low myocardial protein kinase $\mathrm{G}$ activity in heart failure with preserved ejection fraction," Circulation, vol. 126, no. 7, pp. 830-839, 2012.

[42] A. M. Feldman, A. Combes, D. Wagner et al., "The role of tumor necrosis factor in the pathophysiology of heart failure," Journal of the American College of Cardiology, vol. 35, no. 3, pp. 537-544, 2000.

[43] M. Yoshizumi, M. A. Perrella, J. C. Burnett, and M. E. Lee, "Tumor necrosis factor downregulates an endothelial nitric oxide synthase mRNA by shortening its half-life," Circulation Research, vol. 73, no. 1, pp. 205-209, 1993.

[44] K. Bishu, A. Deswal, H. H. Chen et al., "Biomarkers in acutely decompensated heart failure with preserved or reduced ejection fraction," American Heart Journal, vol. 164, no. 5, article e3, pp. 763-770, 2012.

[45] N. M. Hamburg, M. J. Keyes, M. G. Larson et al., "Cross-sectional relations of digital vascular function to cardiovascular risk factors in the Framingham heart study," Circulation, vol. 117, no. 19, pp. 2467-2474, 2008.

[46] E. J. Benjamin, M. G. Larson, M. J. Keyes et al., "Clinical correlates and heritability of flow-mediated dilation in the community: the Framingham heart study," Circulation, vol. 109, no. 5, pp. 613-619, 2004.

[47] E. Akiyama, S. Sugiyama, Y. Matsuzawa et al., "Incremental prognostic significance of peripheral endothelial dysfunction in patients with heart failure with normal left ventricular ejection fraction," Journal of the American College of Cardiology, vol. 60, no. 18, pp. 1778-1786, 2012.

[48] B. A. Borlaug, T. P. Olson, C. S. P. Lam et al., "Global cardiovascular reserve dysfunction in heart failure with preserved ejection fraction," Journal of the American College of Cardiology, vol. 56, no. 11, pp. 845-854, 2010.

[49] P. O. Bonetti, G. M. Pumper, S. T. Higano, D. R. Holmes, J. T. Kuvin, and A. Lerman, "Noninvasive identification of patients with early coronary atherosclerosis by assessment of digital reactive hyperemia," Journal of the American College of Cardiology, vol. 44, no. 11, pp. 2137-2141, 2004.
[50] Y. Matsue, M. Suzuki, W. Nagahori et al., "Endothelial dysfunction measured by peripheral arterial tonometry predicts prognosis in patients with heart failure with preserved ejection fraction," International Journal of Cardiology, vol. 168, no. 1, pp. 36-40, 2013.

[51] N. M. Hamburg, J. Palmisano, M. G. Larson et al., "Relation of brachial and digital measures of vascular function in the community: the framingham heart study," Hypertension, vol. 57, no. 3, pp. 390-396, 2011.

[52] A. Shafiq, C. A. Brawner, H. A. Aldred et al., "Prognostic value of cardiopulmonary exercise testing in heart failure with preserved ejection fraction. The Henry ford HospITal CardioPulmonary EXercise testing (FIT-CPX) project," American Heart Journal, vol. 174, pp. 167-172, 2016.

[53] D. M. Hirai, T. I. Musch, and D. C. Poole, "Exercise training in chronic heart failure: improving skeletal muscle $\mathrm{O}_{2}$ transport and utilization," American Journal of Physiology. Heart and Circulatory Physiology, vol. 309, no. 9, pp. H1419-H1439, 2015.

[54] I. Sarelius and U. Pohl, "Control of muscle blood flow during exercise: local factors and integrative mechanisms," Acta Physiologica, vol. 199, no. 4, pp. 349-365, 2010.

[55] W. C. Little and B. A. Borlaug, "Exercise intolerance in heart failure with preserved ejection fraction: what does the heart have to do with it?" Circulation: Heart Failure, vol. 8, no. 2, pp. 233-235, 2015.

[56] M. Santos, A. R. Opotowsky, A. M. Shah, J. Tracy, A. B. Waxman, and D. M. Systrom, "Central cardiac limit to aerobic capacity in patients with exertional pulmonary venous hypertension: implications for heart failure with preserved ejection fraction," Circulation: Heart Failure, vol. 8, no. 2, pp. 278-285, 2014.

[57] M. J. Haykowsky, P. H. Brubaker, J. M. John, K. P. Stewart, T. M. Morgan, and D. W. Kitzman, "Determinants of exercise intolerance in elderly heart failure patients with preserved ejection fraction," Journal of the American College of Cardiology, vol. 58, no. 3, pp. 265-274, 2011.

[58] J. Shimiaie, J. Sherez, G. Aviram et al., "Determinants of effort intolerance in patients with heart failure," JACC: Heart Failure, vol. 3, no. 10, pp. 803-814, 2015.

[59] B. P. Dhakal, R. Malhotra, R. M. Murphy et al., "Mechanisms of exercise intolerance in heart failure with preserved ejection fraction: the role of abnormal peripheral oxygen extraction," Circulation: Heart Failure, vol. 8, no. 2, pp. 286-294, 2014.

[60] T. J. Anderson, A. Uehata, M. D. Gerhard et al., "Close relation of endothelial function in the human coronary and peripheral circulations," Journal of the American College of Cardiology, vol. 26, no. 5, pp. 1235-1241, 1995.

[61] M. J. Haykowsky, D. M. Herrington, P. H. Brubaker, T. M. Morgan, W. G. Hundley, and D. W. Kitzman, "Relationship of flow-mediated arterial dilation and exercise capacity in older patients with heart failure and preserved ejection fraction," The Journals of Gerontology. Series A, Biological Sciences and Medical Sciences, vol. 68, no. 2, pp. 161-167, 2013.

[62] S. Maréchaux, R. Samson, E. Van Belle et al., "Vascular and microvascular endothelial function in heart failure with preserved ejection fraction," Journal of Cardiac Failure, vol. 22, no. 1, pp. 3-11, 2016.

[63] J. F. Lee, Z. Barrett-O'Keefe, R. S. Garten et al., "Evidence of microvascular dysfunction in heart failure with preserved ejection fraction," Heart, vol. 102, no. 4, pp. 278-284, 2016. 
[64] E. Yamamoto, Y. Hirata, T. Tokitsu et al., "The pivotal role of eNOS uncoupling in vascular endothelial dysfunction in patients with heart failure with preserved ejection fraction," International Journal of Cardiology, vol. 190, pp. 335-337, 2015.

[65] S. Balmain, N. Padmanabhan, W. R. Ferrell, J. J. Morton, and J. J. V. McMurray, "Differences in arterial compliance, microvascular function and venous capacitance between patients with heart failure and either preserved or reduced left ventricular systolic function," European Journal of Heart Failure, vol. 9, no. 9, pp. 865-871, 2007.

[66] K. E. Pyke and M. E. Tschakovsky, "The relationship between shear stress and flow-mediated dilatation: implications for the assessment of endothelial function," The Journal of Physiology, vol. 568, Part 2, pp. 357-369, 2005.

[67] D. H. Thijssen, M. A. Black, K. E. Pyke et al., "Assessment of flow-mediated dilation in humans: a methodological and physiological guideline," American Journal of Physiology. Heart and Circulatory Physiology, vol. 300, no. 1, pp. H2-H12, 2011.

[68] M. J. Haykowsky, P. H. Brubaker, T. M. Morgan, S. Kritchevsky, J. Eggebeen, and D. W. Kitzman, "Impaired aerobic capacity and physical functional performance in older heart failure patients with preserved ejection fraction: role of lean body mass," The Journals of Gerontology. Series A, Biological Sciences and Medical Sciences, vol. 68, no. 8, pp. 968-975, 2013.

[69] M. J. Haykowsky, E. J. Kouba, P. H. Brubaker, B. J. Nicklas, J. Eggebeen, and D. W. Kitzman, "Skeletal muscle composition and its relation to exercise intolerance in older patients with heart failure and preserved ejection fraction," The American Journal of Cardiology, vol. 113, no. 7, pp. 1211-1216, 2014.

[70] A. J. A. Molina, M. S. Bharadwaj, C. Van Horn et al., "Skeletal muscle mitochondrial content, oxidative capacity, and Mfn2 expression are reduced in older patients with heart failure and preserved ejection fraction and are related to exercise intolerance," JACC: Heart Failure, vol. 4, no. 8, pp. 0-9, 2016.

[71] T. S. Bowen, N. P. L. Rolim, T. Fischer et al., "Heart failure with preserved ejection fraction induces molecular, mitochondrial, histological, and functional alterations in rat respiratory and limb skeletal muscle," European Journal of Heart Failure, vol. 17, no. 3, pp. 263-272, 2015.

[72] D. W. Kitzman, B. Nicklas, W. E. Kraus et al., "Skeletal muscle abnormalities and exercise intolerance in older patients with heart failure and preserved ejection fraction," American Journal of Physiology. Heart and Circulatory Physiology, vol. 306, no. 9, pp. H1364-H1370, 2014.

[73] J. F. Lee, Z. Barrett-O'Keefe, A. D. Nelson et al., "Impaired skeletal muscle vasodilation during exercise in heart failure with preserved ejection fraction," International Journal of Cardiology, vol. 211, pp. 14-21, 2016.

[74] D. W. Kitzman, P. H. Brubaker, D. M. Herrington et al., "Effect of endurance exercise training on endothelial function and arterial stiffness in older patients with heart failure and preserved ejection fraction: a randomized, controlled, single-blind trial," Journal of the American College of Cardiology, vol. 62, no. 7, pp. 584-592, 2013.

[75] F. L. Dini, L. Ghiadoni, U. Conti et al., "Coronary flow Reserve in Idiopathic Dilated Cardiomyopathy: relation with left Ventricular Wall stress, natriuretic peptides, and endothelial dysfunction," Journal of the American Society of Echocardiography, vol. 22, no. 4, pp. 354-360, 2009.
[76] M. Snoer, T. Monk-Hansen, R. H. Olsen et al., "Coronary flow reserve as a link between diastolic and systolic function and exercise capacity in heart failure," European Heart Journal. Cardiovascular Imaging, vol. 14, no. 7, pp. 677683, 2013.

[77] B. Anantharam, R. Janardhanan, S. Hayat et al., "Coronary flow reserve assessed by myocardial contrast echocardiography predicts mortality in patients with heart failure," European Journal of Echocardiography, vol. 12, no. 1, pp. 69-75, 2011.

[78] C. Tschöpe, C.-T. Bock, M. Kasner et al., "High prevalence of cardiac parvovirus B19 infection in patients with isolated left ventricular diastolic dysfunction," Circulation, vol. 111, no. 7, pp. 879-886, 2005.

[79] M. Teragaki, S. Yanagi, I. Toda et al., "Coronary flow reserve correlates left ventricular diastolic dysfunction in patients with dilated cardiomyopathy," Catheterization and Cardiovascular Interventions, vol. 58, no. 1, pp. 43-50, 2003.

[80] M. Snoer, T. Monk-Hansen, R. Olsen et al., "Insulin resistance and exercise tolerance in heart failure patients: linkage to coronary flow reserve and peripheral vascular function," Cardiovascular Diabetology, vol. 11, no. 1, p. 97, 2012.

[81] D. J. Pinsky, S. Patton, S. Mesaros et al., "Mechanical transduction of nitric oxide synthesis in the beating heart," Circulation Research, vol. 81, no. 3, pp. 372-379, 1997.

[82] M. J. Kohr, J. P. Davis, and M. T. Ziolo, "Peroxynitrite increases protein phosphatase activity and promotes the interaction of phospholamban with protein phosphatase $2 \mathrm{a}$ in the myocardium," Nitric Oxide, vol. 20, no. 3, pp. 217-221, 2009.

[83] N. Hamdani, C. Franssen, A. Lourenço et al., "Myocardial titin hypophosphorylation importantly contributes to heart failure with preserved ejection fraction in a rat metabolic risk model," Circulation: Heart Failure, vol. 6, no. 6, pp. 12391249, 2013.

[84] E. Takimoto, H. C. Champion, M. Li et al., "Chronic inhibition of cyclic GMP phosphodiesterase 5A prevents and reverses cardiac hypertrophy," Nature Medicine, vol. 11, no. 2, pp. 214-222, 2005.

[85] J. Hou, H. Kato, R. A. Cohen, A. V. Chobanian, and P. Brecher, "Angiotensin II-induced cardiac fibrosis in the rat is increased by chronic inhibition of nitric oxide synthase," The Journal of Clinical Investigation, vol. 96, no. 5, pp. 2469-2477, 1995.

[86] C. S. P. Lam, V. L. Roger, R. J. Rodeheffer, B. Borlaug, F. T. Enders, and M. M. Redfield, "Pulmonary hypertension in heart failure with preserved ejection fraction: a communitybased study," Journal of the American College of Cardiology, vol. 53, no. 13, pp. 1119-1126, 2009.

[87] B. A. Borlaug, R. A. Nishimura, P. Sorajja, C. S. P. Lam, and M. M. Redfield, "Exercise hemodynamics enhance diagnosis of early heart failure with preserved ejection fraction," Circulation: Heart Failure, vol. 3, no. 5, pp. 588-595, 2010.

[88] B. A. Borlaug, G. C. Kane, V. Melenovsky, and T. P. Olson, "Abnormal right ventricular-pulmonary artery coupling with exercise in heart failure with preserved ejection fraction," European Heart Journal, vol. 37, no. 43, pp. 3293-3302, 2016, ehw 241.

[89] S. F. Mohammed, I. Hussain, Abou Ezzeddine OF et al., "Right ventricular function in heart failure with preserved ejection fraction: a community-based study," Circulation, vol. 130, no. 25, pp. 2310-2320, 2014. 
[90] M. J. Andersen, S. J. Hwang, G. C. Kane et al., "Enhanced pulmonary vasodilator reserve and abnormal right ventricular: pulmonary artery coupling in heart failure with preserved ejection fraction," Circulation: Heart Failure, vol. 8, no. 3, pp. 542-550, 2015.

[91] B. Driss A, C. Devaux, D. Henrion et al., "Hemodynamic stresses induce endothelial dysfunction and remodeling of pulmonary artery in experimental compensated heart failure," Circulation, vol. 101, no. 23, 2000.

[92] C. S. P. Lam and D. L. Brutsaert, "Endothelial dysfunction: a pathophysiologic factor in heart failure with preserved ejection fraction," Journal of the American College of Cardiology, vol. 60, no. 18, pp. 1787-1789, 2012.

[93] Y.-C. Lai, D. M. Tabima, J. J. Dube et al., "SIRT3AMPK activation by nitrite and metformin improves hyperglycemia and normalizes pulmonary hypertension associated with heart failure with preserved ejection fraction (PH-HFpEF)," Circulation, vol. 133, no. 8, pp. 717-731, 2016.

[94] M. Farrero, I. Blanco, M. Batlle et al., "Pulmonary hypertension is related to peripheral endothelial dysfunction in heart failure with preserved ejection fraction," Circulation: Heart Failure, vol. 7, no. 5, pp. 791-798, 2014.

[95] C. J. Cooper, M. J. Landzberg, T. J. Anderson et al., "Role of nitric oxide in the local regulation of pulmonary vascular resistance in humans," Circulation, vol. 93, no. 2, pp. 266271, 1996.

[96] V. F. M. Segers, D. L. Brutsaert, and G. W. De Keulenaer, "Pulmonary hypertension and right heart failure in heart failure with preserved left ventricular ejection fraction," Current Opinion in Cardiology, vol. 27, no. 3, pp. 273280, 2012.

[97] R. Andrea, A. López-Giraldo, C. Falces et al., "Lung function abnormalities are highly frequent in patients with heart failure and preserved ejection fraction," Heart, Lung \& Circulation, vol. 23, no. 3, pp. 273-279, 2014.

[98] T. P. Olson, B. D. Johnson, and B. A. Borlaug, "Impaired pulmonary diffusion in heart failure with preserved ejection fraction," JACC: Heart Failure, vol. 4, no. 6, pp. 490-498, 2016.

[99] B. M. Massie, P. E. Carson, J. J. McMurray et al., "Irbesartan in patients with heart failure and preserved ejection fraction," The New England Journal of Medicine, vol. 359, no. 23, pp. 2456-2467, 2008.

[100] H. L. Hillege, D. Nitsch, M. A. Pfeffer et al., "Renal function as a predictor of outcome in a broad spectrum of patients with heart failure," Circulation, vol. 113, no. 5, pp. 671-678, 2006.

[101] K. Damman, M. A. E. Valente, A. A. Voors, C. M. O'Connor, D. J. van Veldhuisen, and H. L. Hillege, "Renal impairment, worsening renal function, and outcome in patients with heart failure: an updated meta-analysis," European Heart Journal, vol. 35, no. 7, pp. 455-469, 2014.

[102] A. H. Van Craenenbroeck, E. M. Van Craenenbroeck, K. Van Ackeren et al., "Effect of moderate aerobic exercise training on endothelial function and arterial stiffness in CKD stages 3-4: a randomized controlled trial," American Journal of Kidney Diseases, vol. 66, no. 2, pp. 285-296, 2015.

[103] Y. Hirata, S. Sugiyama, E. Yamamoto et al., "Endothelial function and cardiovascular events in chronic kidney disease," International Journal of Cardiology, vol. 173, no. 3, pp. 481-486, 2014.
[104] A. Gevaert, A. H. Van Craenenbroeck, B. Shivalkar, K. Lemmens, C. J. Vrints, and E. M. Van Craenenbroeck, "Preclinical diastolic dysfunction is related to impaired endothelial function in chronic kidney disease patients (Abstract)," European Heart Journal - Cardiovascular Imaging, vol. 16, Supplement 2, p. S4, 2015.

[105] J. M. ter Maaten, K. Damman, M. C. Verhaar et al., "Connecting heart failure with preserved ejection fraction and renal dysfunction: the role of endothelial dysfunction and inflammation," European Journal of Heart Failure, vol. 18, no. 6, pp. 588-598, 2016.

[106] A. H. Van Craenenbroeck, E. M. Van Craenenbroeck, E. Kouidi, C. J. Vrints, M. M. Couttenye, and V. M. Conraads, "Vascular effects of exercise training in CKD: current evidence and pathophysiological mechanisms," Clinical Journal of the American Society of Nephrology, vol. 9, no. 7, pp. 13051318, 2014.

[107] W. Mullens, Z. Abrahams, G. S. Francis et al., "Importance of venous congestion for worsening of renal function in advanced decompensated heart failure," Journal of the American College of Cardiology, vol. 53, no. 7, pp. 589-596, 2009.

[108] D. A. Klein, D. H. Katz, L. Beussink-Nelson, C. L. Sanchez, T. A. Strzelczyk, and S. J. Shah, "Association of Chronic Kidney Disease with Chronotropic Incompetence in heart failure with preserved ejection fraction," The American Journal of Cardiology, vol. 116, no. 7, pp. 1093-1100, 2015.

[109] W. H. W. Tang and W. Mullens, "Cardiorenal syndrome in decompensated heart failure," Heart, vol. 96, no. 4, pp. 255260, 2010.

[110] M. Damkjær, M. Vafaee, M. L. Møller et al., "Renal cortical and medullary blood flow responses to altered NO availability in humans," American Journal of Physiology. Regulatory, Integrative and Comparative Physiology, vol. 299, no. 6, pp. R1449-R1455, 2010.

[111] C. G. Van Dijk, N. R. Oosterhuis, Y. J. Xu et al., "Distinct endothelial cell responses in the heart and kidney microvasculature characterize the progression of heart failure with preserved ejection fraction in the obese ZSF1 rat with Cardiorenal metabolic Syndrome," Circulation: Heart Failure, vol. 9, no. 4, article e002760, 2016.

[112] F. P. Brouwers, R. A. de Boer, P. van der Harst et al., "Incidence and epidemiology of new onset heart failure with preserved versus reduced ejection fraction in a community-based cohort: 11 year follow-up of PREVEND," European Heart Journal, vol. 34, no. 19, pp. 1424-1431, 2013.

[113] S. Rostand and T. Drueke, "Parathyroid hormone, vitamin D, and cardiovascular disease in chronic renal failure," Kidney International, vol. 56, no. 2, pp. 383-392, 1999.

[114] N. Chitalia, A. Recio-Mayoral, J. Kaski, and D. Banerjee, "Vitamin D deficiency and endothelial dysfunction in nondialysis chronic kidney disease patients," Atherosclerosis, vol. 220, no. 1, pp. 265-268, 2012.

[115] K. Jie, M. Zaikova, M. Bergevoet et al., "Progenitor cells and vascular function are impaired in patients with chronic kidney disease," Nephrology Dialysis Transplantation, vol. 25, no. 6, pp. 1875-1882, 2010.

[116] H. Oberleithner, C. Riethmuller, H. Schillers, G. A. Mac Gregor, H. E. de Wardener, and M. Hausberg, "Plasma sodium stiffens vascular endothelium and reduces nitric oxide release," Proceedings of the National Academy of Sciences, vol. 104, no. 41, pp. 16281-16286, 2007. 
[117] F. Edelmann, G. Gelbrich, H.-D. Düngen et al., "Exercise training improves exercise capacity and diastolic function in patients with heart failure with preserved ejection fraction (ex-DHF)," Journal of the American College of Cardiology, vol. 58, no. 17, pp. 1780-1791, 2011.

[118] D. W. Kitzman, P. H. Brubaker, T. M. Morgan, K. P. Stewart, and W. C. Little, "Exercise training in older patients with heart failure and preserved ejection fraction: a randomized, controlled, single-blind trial," Circulation: Heart Failure, vol. 3, no. 6, pp. 659-667, 2010.

[119] D. W. Kitzman, P. Brubaker, T. Morgan et al., "Effect of caloric restriction or aerobic exercise training on peak oxygen consumption and quality of life in obese older patients with heart failure with preserved ejection fraction," Journal of the American Medical Association, vol. 315, no. 1, p. 36, 2016.

[120] A. J. Alves, F. Ribeiro, E. Goldhammer et al., "Exercise training improves diastolic function in heart failure patients," Medicine and Science in Sports and Exercise, vol. 44, no. 5, pp. 776-785, 2012.

[121] N. A. Smart, B. Haluska, L. Jeffries, and D. Leung, "Exercise training in heart failure with preserved systolic function: a randomized controlled trial of the effects on cardiac function and functional capacity," Congestive Heart Failure, vol. 18, no. 6, pp. 295-301, 2012.

[122] R. A. Gary, C. A. Sueta, M. Dougherty et al., "Home-based exercise improves functional performance and quality of life in women with diastolic heart failure," Heart Lung, vol. 33, no. 4, pp. 210-218, 2004.

[123] E. Chan, F. Giallauria, C. Vigorito, and N. A. Smart, "Exercise training in heart failure patients with preserved ejection fraction: a systematic review and meta-analysis," Monaldi Archive of Chest Diseases, vol. 86, no. 1-2, p. 759, 2016.

[124] H. Fukuta, T. Goto, K. Wakami, and N. Ohte, "Effects of drug and exercise intervention on functional capacity and quality of life in heart failure with preserved ejection fraction: A meta-analysis of randomized controlled trials," European Journal of Preventive Cardiology, vol. 23, no. 1, pp. 78-85, 2016.

[125] A. Pandey, A. Parashar, and D. J. Kumbhani, "Exercise training in patients with heart failure and preserved ejection fraction: meta-analysis of randomized control trials," Circulation: Heart Failure, vol. 8, no. 1, pp. 33-40.

[126] U. Wisløff, A. Støylen, J. P. Loennechen et al., "Superior cardiovascular effect of aerobic interval training versus moderate continuous training in heart failure patients: a randomized study," Circulation, vol. 115, no. 24, pp. 3086-3094, 2007.

[127] Ø. Ellingsen, M. Halle, V. M. Conraads et al., "High intensity interval training in heart failure patients with reduced ejection fraction," Circulation, vol. 135, no. 9, pp. 839-849, 2017.

[128] S. S. Angadi, F. Mookadam, C. D. Lee, W. J. Tucker, M. J. Haykowsky, and G. Gaesser, "A. High-intensity interval training versus moderate-intensity continuous exercise training in heart failure with preserved ejection fraction: a pilot study," Journal of Applied Physiology, vol. 119, no. 6, pp. 753-758, 2015.

[129] C. Suchy, L. Massen, O. Rognmo et al., "Optimising exercise training in prevention and treatment of diastolic heart failure (OptimEx-CLIN): rationale and design of a prospective, randomised, controlled trial," European
Journal of Preventive Cardiology, vol. 21, no. 2S, pp. 18-25, 2014.

[130] V. Adams, A. Linke, N. Kränkel et al., "Impact of regular physical activity on the $\mathrm{NAD}(\mathrm{P}) \mathrm{H}$ oxidase and angiotensin receptor system in patients with coronary artery disease," Circulation, vol. 111, no. 5, pp. 555-562, 2005.

[131] V. M. Conraads, E. M. Van Craenenbroeck, C. De Maeyer, A. M. Van Berendoncks, P. J. Beckers, and C. J. Vrints, "Unraveling new mechanisms of exercise intolerance in chronic heart failure. Role of exercise training," Heart Failure Reviews, vol. 18, no. 1, pp. 65-77, 2013.

[132] C. Urbich and S. Dimmeler, "Endothelial progenitor cells: characterization and role in vascular biology," Circulation Research, vol. 95, no. 4, pp. 343-353, 2004.

[133] E. M. Van Craenenbroeck and V. M. Conraads, "Mending injured endothelium in chronic heart failure: a new target for exercise training," International Journal of Cardiology, vol. 166, no. 2, pp. 310-314, 2013.

[134] E. M. Van Craenenbroeck, P. J. Beckers, N. M. Possemiers et al., "Exercise acutely reverses dysfunction of circulating angiogenic cells in chronic heart failure," European Heart Journal, vol. 31, no. 15, pp. 1924-1934, 2010.

[135] E. M. Van Craenenbroeck, V. Y. Hoymans, P. J. Beckers et al., "Exercise training improves function of circulating angiogenic cells in patients with chronic heart failure," Basic Research in Cardiology, vol. 105, no. 5, pp. 665676, 2010

[136] M. Sandri, M. Viehmann, V. Adams et al., "Chronic heart failure and aging-effects of exercise training on endothelial function and mechanisms of endothelial regeneration: results from the Leipzig exercise intervention in chronic heart failure and aging (LEICA) study," European Journal of Preventive Cardiology, vol. 23, no. 4, pp. 349-358, 2016.

[137] T. D. Trippel, V. Holzendorf, M. Halle et al., "Ghrelin and hormonal markers under exercise training in patients with heart failure with preserved ejection fraction: results from the ex-DHF pilot study," ESC Heart Failure, vol. 4, no. 1, pp. 56-65, 2017.

[138] R. Hambrecht, A. Wolf, S. Gielen et al., "Effect of exercise on coronary endothelial function in patients with coronary artery disease," The New England Journal of Medicine, vol. 342, no. 7, pp. 454-460, 2000.

[139] V. M. Conraads, N. Pattyn, C. De Maeyer et al., “Aerobic interval training and continuous training equally improve aerobic exercise capacity in patients with coronary artery disease: the SAINTEX-CAD study," International Journal of Cardiology, vol. 179, pp. 203-210, 2015.

[140] Y. Higashi, S. Sasaki, N. Sasaki et al., "Daily aerobic exercise improves reactive hyperemia in patients with essential hypertension," Hypertension, vol. 33, no. 1, Part 2, pp. 591-597, 1999.

[141] M. J. Haykowsky, P. H. Brubaker, K. P. Stewart, T. M. Morgan, J. Eggebeen, and D. W. Kitzman, "Effect of endurance training on the determinants of peak exercise oxygen consumption in elderly patients with stable compensated heart failure and preserved ejection fraction," Journal of the American College of Cardiology, vol. 60, no. 2, pp. 120-128, 2012.

[142] T.-C. Fu, N.-I. Yang, C.-H. Wang et al., “Aerobic interval training elicits different hemodynamic adaptations between heart failure patients with preserved and reduced ejection 
fraction," American Journal of Physical Medicine \& Rehabilitation, vol. 95, no. 1, pp. 15-27, 2016.

[143] M. C. Corretti, T. J. Anderson, E. J. Benjamin et al., "Guidelines for the ultrasound assessment of endothelialdependent flow- mediated vasodilation of the brachial artery: a report of the International brachial artery reactivity task force," Journal of the American College of Cardiology, vol. 39, no. 2, pp. 257-265, 2002.

[144] D. Legallois, A. Belin, S. V. Nesterov et al., "Cardiac rehabilitation improves coronary endothelial function in patients with heart failure due to dilated cardiomyopathy: a positron emission tomography study," European Journal of Preventive Cardiology, vol. 23, no. 2, pp. 129-136, 2016.

[145] S. J. Shah, D. H. Katz, and R. C. Deo, "Phenotypic Spectrum of heart failure with preserved ejection fraction," Heart Failure Clinics, vol. 10, no. 3, pp. 407-418, 2014.

[146] S. J. Shah, D. W. Kitzman, B. A. Borlaug et al., "Phenotypespecific treatment of heart failure with preserved ejection fraction," Circulation, vol. 134, no. 1, pp. 73-90, 2016.

[147] S. J. Shah, D. H. Katz, S. Selvaraj et al., "Phenomapping for novel classification of heart failure with preserved ejection fraction," Circulation, vol. 131, no. 3, pp. 269-279, 2014.

[148] M. Obokata, Y. N. V. Reddy, S. V. Pislaru, V. Melenovsky, and B. A. Borlaug, "Evidence supporting the existence of a distinct obese phenotype of heart failure with preserved ejection fraction," Circulation, 2017.

[149] B. Pieske, J. Butler, G. Filippatos et al., "Rationale and design of the SOluble guanylate Cyclase stimulatoR in heArT failurE Studies (SOCRATES)," European Journal of Heart Failure, vol. 16, no. 9, pp. 1026-1038, 2014.

[150] W. G. Hundley, E. Bayram, C. A. Hamilton et al., "Leg flowmediated arterial dilation in elderly patients with heart failure and normal left ventricular ejection fraction," American Journal of Physiology. Heart and Circulatory Physiology, vol. 292, no. 3, pp. H1427-H1434, 2006.

[151] S. Kishimoto, M. Kajikawa, T. Maruhashi et al., "Endothelial dysfunction and abnormal vascular structure are simultaneously present in patients with heart failure with preserved ejection fraction," International Journal of Cardiology, vol. 231, pp. 181-187, 2017.

[152] D. Vitiello, F. Harel, R. M. Touyz et al., "Changes in cardiopulmonary reserve and peripheral arterial function concomitantly with subclinical inflammation and oxidative stress in patients with heart failure with preserved ejection fraction," International Journal of Vascular Medicine, vol. 2014, Article ID 917271, 8 pages, 2014. 


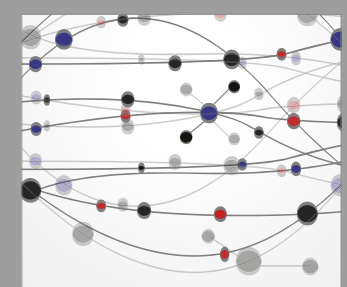

The Scientific World Journal
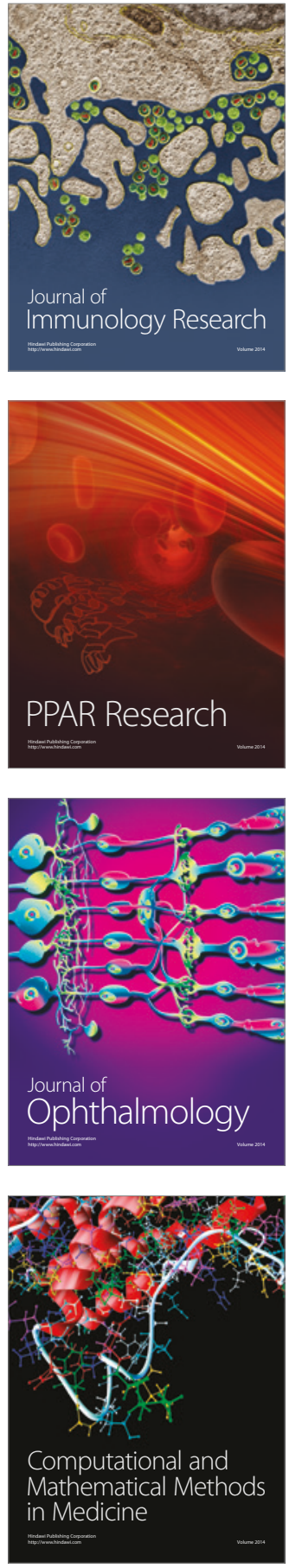

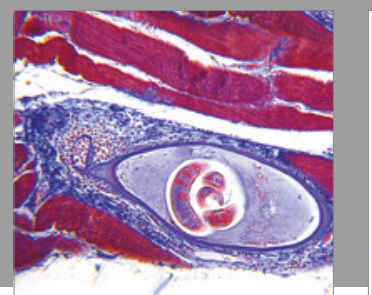

Gastroenterology Research and Practice
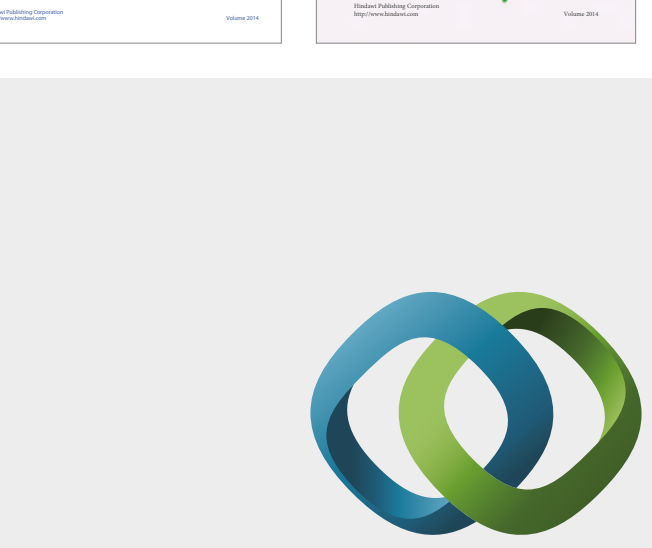

\section{Hindawi}

Submit your manuscripts at

https://www.hindawi.com
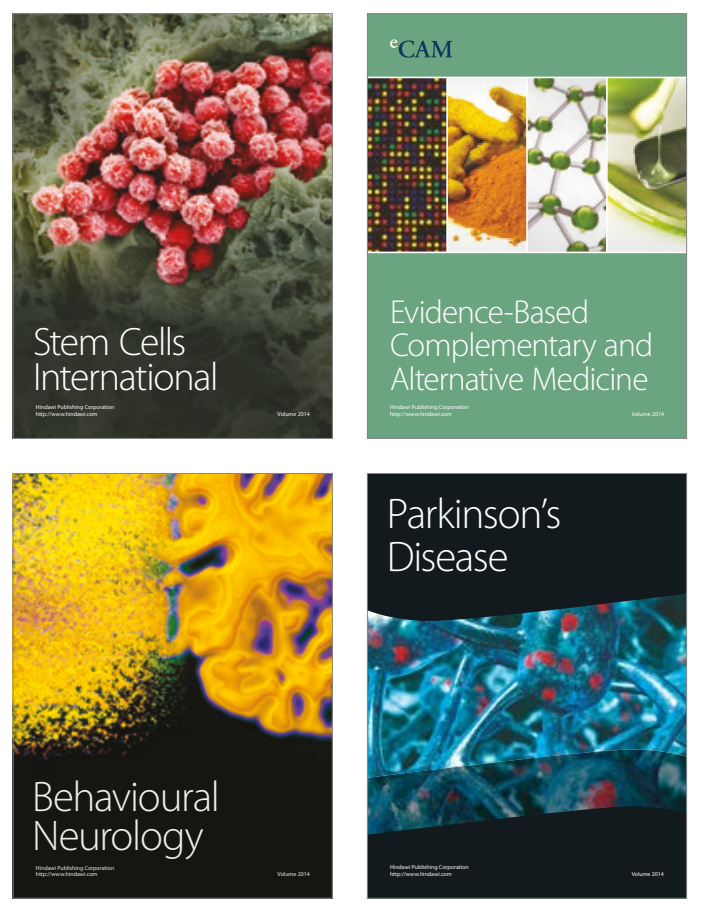
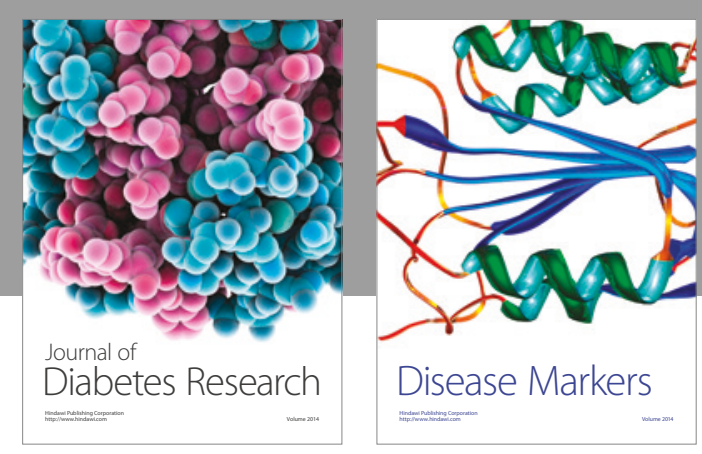

Disease Markers
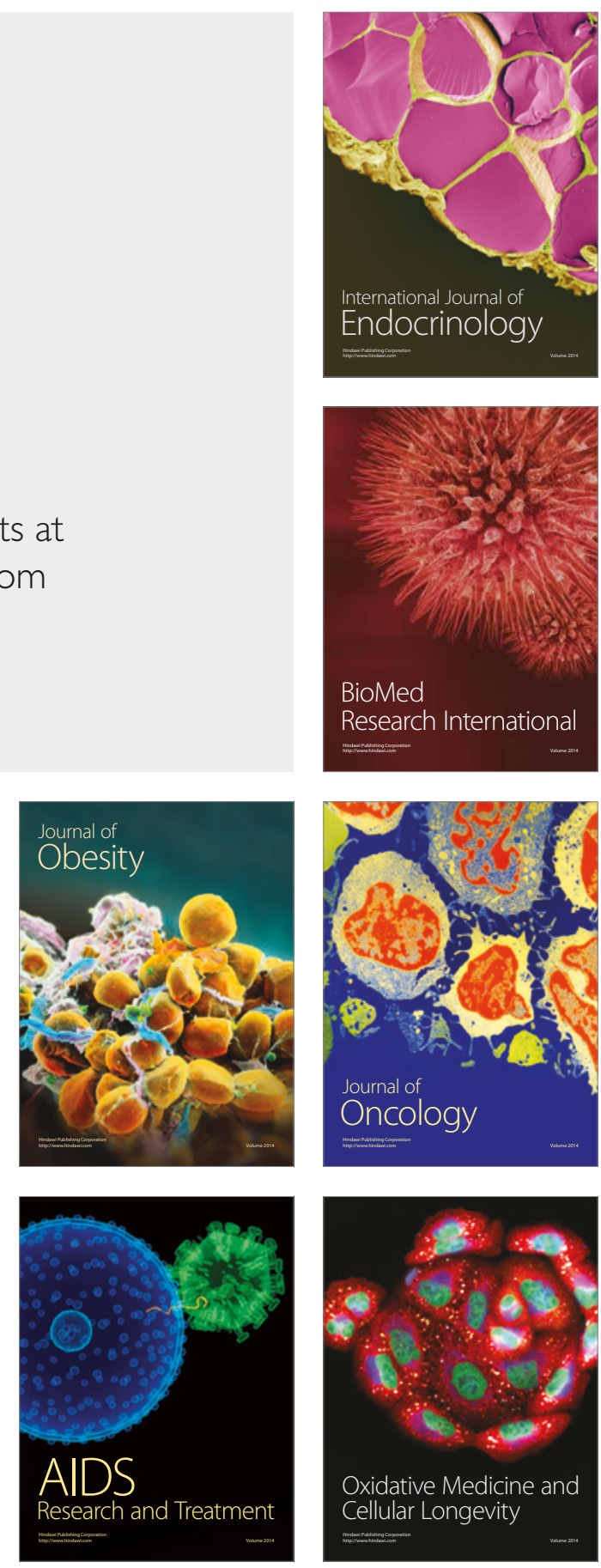